\title{
Hybrid AC/DC Microgrid Testing Facility for Energy Management in Commercial Buildings \\ Domagoj Leskarac ${ }^{1}$, Mojtaba Moghimi ${ }^{1}$, Jiannan Liu ${ }^{1}$, Wayne Water ${ }^{1}$, Junwei Lu ${ }^{1}$, Sascha Stegen ${ }^{1}$
}

\begin{abstract}
With ever increasing energy generation diversity and energy storage becoming affordable, distribution networks are becoming more complex than ever before. This complexity can be utilized to benefit the distribution networks as well as end consumers in the form of controlled Microgrids. Microgrids are not simply distributed generation and energy storage systems; solar systems and battery banks, rather a complete design of hardware and software for specific uses and users. All the different elements need to be designed to work together to provide stable, efficient and sustainable power delivery to the end user. An experimental Hybrid-Microgrid testing facility is presented in this paper that implements highefficiency distribution architectures combining both $A C$ and DC networks. This testing facility provides a research testbed for investigating different aspects of Microgrid systems, employing a total of $15.5 \mathrm{~kW}$ of reconfigurable Solar PV and $80 \mathrm{kWh}$ of lithium energy storage on a $145 \mathrm{kVA}$ commercial building load located at Griffith University. Implementation results along with control system simulation results are presented in this paper for distributed renewable generation, Static Synchronous Compensators, advanced control methodologies and forecasting methods for energy management purposes.
\end{abstract}

Keywords: Hybrid AC/DC Microgrid, DC Bus, Smart Grids, Static Synchronous Compensators, Control Systems, Communication and Monitoring Systems

\footnotetext{
${ }^{1}$ School of Engineering and Built Environment, Griffith University, Nathan Campus 4111, Brisbane, Australia; email: D.Leskarac@Griffith.edu.au
} 


\section{Introduction}

Distribution networks have seen a large increase in distributed generation over the past decade, primarily in the form of distributed renewable energy sources. Australia has shown great interest in distributed generation with over 2.5 million small-scale installations nationwide [1], predominantly solar Photovoltaic (PV) systems. As the price of Solar PV systems has reduced with time, the size of installations has on average increased from approximately $2.5 \mathrm{~kW}$ in 2011 to $4.9 \mathrm{~kW}$ in 2015 . A total of over 130000 residential sized systems $(1 \mathrm{kw}-10 \mathrm{~kW})$ and $6800 \mathrm{commercial}$ sized systems $(10 \mathrm{~kW}-100 \mathrm{~kW})$ were installed in 2015 across Australia [2]. Overall, the integration of distributed generation is a positive in improving the local distribution efficiency, but in some areas where high intermittent renewable energy penetration and low daily loads exist, the benefits of improved efficiency can be outweighed by voltage regulation problems, design frequency deviation and reverse power flow [3-8]. There have been a number of mitigation strategies proposed to curb the impact of the intermittent energy sources, primarily through the integration of energy storage. By implementing sufficient energy storage in conjunction with distributed generation and control systems, a Microgrid (MG) can be ascertained. The Institute of Electrical and Electronics Engineers (IEEE) defines an MG in [9], where the definition can be simplified to a grid that integrates the following properties:

- Desirable operation in parallel with the distribution grid

- Desirable operation as an independent "island" network

- Implementation of control equipment to transition to and from the distribution grid

This base criterion indicates that the implementation of an MG should benefit the distribution network and the connected loads without compromising either network when switched between islanding and grid-connected modes. The MG should benefit the distribution network in peak demand management, power factor maintenance, voltage control and ensure that harmonics are controlled and minimized. These utility stability measures also benefit loads by ensuring a clean and stable power source is present at all times, irrespective of the status of the distribution grid. The stable and scalable formation of an MG has been the topic of significant MG research. There are several MGs testing and simulation facilities along with full sized pilot MG sites around the world, each providing an opportunity to test and analyze different elements within MGs. Europe has invested heavily in MG research and development, currently with over 211 SmartGrid related projects underway within the continent [10]. As predominately $A C$ is utilized for power distribution, a large number of MG testing facilities and pilot sites are built upon this backbone. MG testing facilities such as the Institute for Systems and Computer Engineering, Technology and Science (INESC TEC) in Portugal [11] and larger pilot scale sites such as the Zhejiang Electric Power Test and Research Institute in China [12] and The Tianjin University MG Testbed in China [13], utilize multiple sources of distributed generation (DG), energy storage, power converters and load types on an AC bus to optimize control methods and analysis power characteristics between the different interconnected elements.

The aforementioned MG testing networks are primarily composed of an AC bus, whereas it is possible to improve overall efficiencies by operating some elements with a DC bus [14, 15]. DC MGs have been proposed as an alternate solution to the more common AC MG by a number of research institutions, particularly those with a focus on Plug-in Hybrid Vehicles (PEVs) [16-19]. With the integration of an internal DC bus network, it is possible to connect DC loads, sources, and energy storage without multiple power conversion stages. In the same regard, connecting onto a DC bus is simplified as there are no issues with synchronization or reactive power [20]. Even though DC MGs show signs of promising 
efficiency improvements and network simplicity, the majority of loads are still interconnected via an AC link. By combining the positive elements between the two types of MG topologies, a hybrid AC/DC MG (H-MG) can be obtained. The H-MG philosophy correlates DC sources to $\mathrm{DC}$ loads along with $A C$ sources to $A C$ loads. In the case of solar PV, battery energy storage and PEVs, all elements produce or require a DC network. If voltage and power requirements are met, these elements could be connected as separate nodes on a DC bus [21]. By reducing conversion stages to end use power in both forms, an overall greater efficiency can be obtained within the distribution network.

An interpretation of an H-MG network can be visualized in Fig. 1, where both an AC and DC bus is present across compatible loads and sources. In this diagram, the AC bus is connected to the point of common coupling (PCC) to the LV distribution grid. It is necessary to maintain the PCC on the AC side as switching at LV distribution grid voltages is fairly simple. The interlink between AC and DC can be done through bidirectional converters, but utilizing distributed Static Synchronous Compensators (Statcom) would provide better control of voltage, harmonics and reactive power [22-24]. As the H-MG is inherently more complicated than that of a single AC or DC MG, control and communication systems form an important and key role within the H-MG [25]. By presenting an element of control, interconnecting energy storage systems and PEV on a DC bus can be achieved without the use of additional conversion stages, improving the H-MG overall efficiency. As such a comprehensive control strategy is required to properly implement a reliable and stable $\mathrm{H}$ MG. A three level control system has been identified within the literature; primary, secondary and tertiary control that normalizes the control strategies between the different MG structures [26-28]. Primary control entails a form of droop control adjusting voltage, current, and frequency, secondary control maintains power quality; harmonics, reactive power and transients while tertiary control forms the energy management and power flow control.

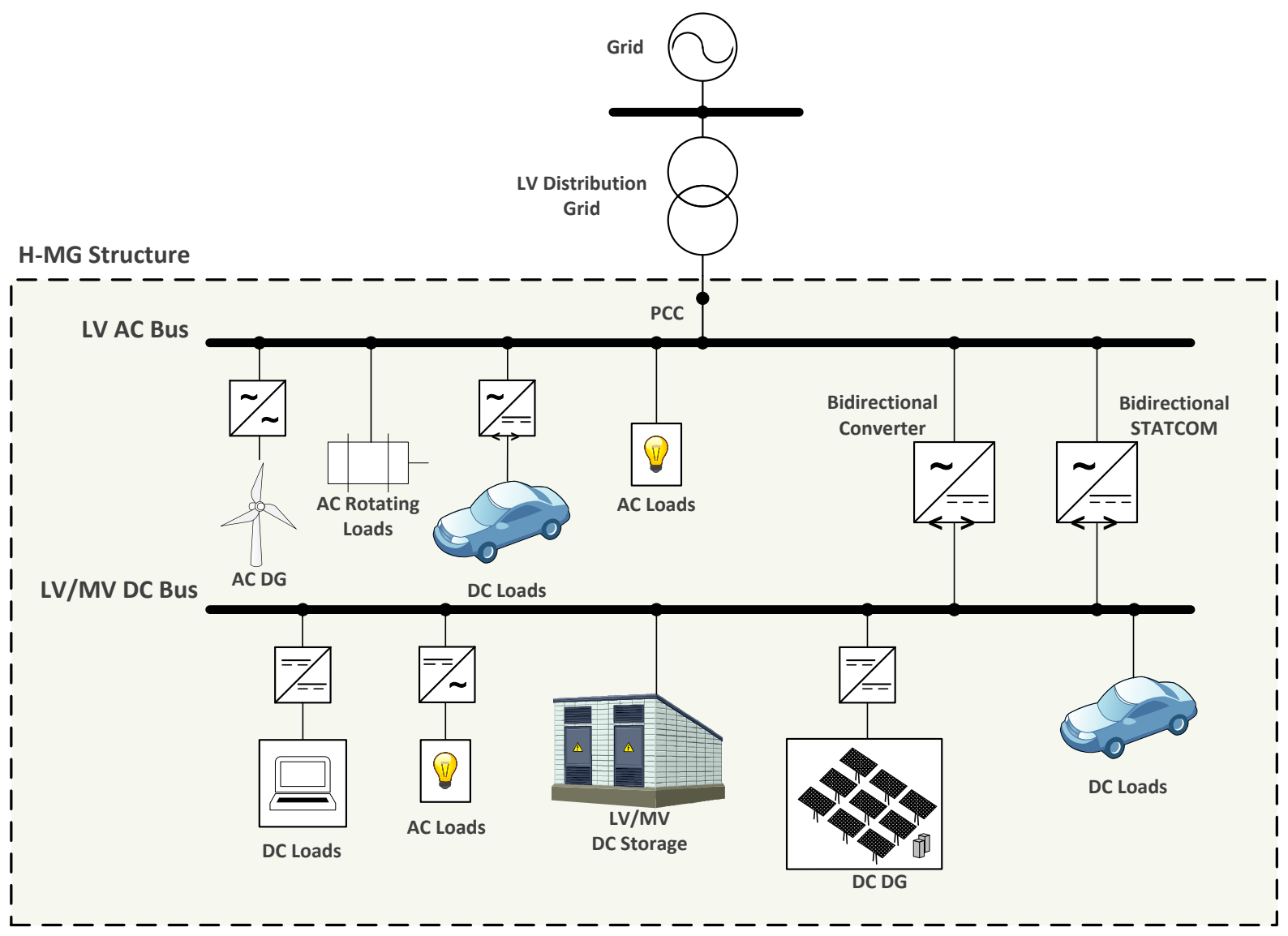

Fig. 1 H-MG Conceptual Diagram 
An H-MG testing facility has been established at Griffith University in Brisbane, Australia at the N44 Building [29, 30]. This facility is constructed on a commercial building with varying daily power quality to undertake investigations into commercial building peak demand energy management through utilization of solar PV [31, 32], wind turbines, energy storage, Statcom voltage and reactive power control [23], and electric vehicle charging and discharging scheduling control [33, 34], and forecasting algorithms [35]. The renewable energy resources located at the H-MG at Griffith consist primarily of solar PV. The solar PV consists of several series connected arrays coupled with SMA ${ }^{\circledR}$ inverters. One of the arrays is connected to Elevare ${ }^{\circledR}$ Energy DC/DC converters which form the basis of a DC bus on the solar PV level. Two types of Statcoms are employed, a single-phase 10kVA Power $I^{\circledR}$ Statcom and a three-phase 30kVA Statcom from Elevare Energy. The utilization of these two Statcom types provides the H-MG with the control necessary to satisfy the IEEE standard on MGs. Energy storage is in the form of two Kokam ${ }^{\circledR}$ lithium batteries, configured in two LV busses: $200 \mathrm{~V}-300 \mathrm{~V}$ and $700 \mathrm{~V}-800 \mathrm{~V}$. The bus voltages fall in line with the high voltage Statcoms requirements and provide a real DC bus for PEV connections; which range from $300 \mathrm{~V}$ DC $-500 \mathrm{~V}$ DC based upon current physical connector limitations [36]. There is an extensive communication system encompassing several communication protocols to monitor and control different elements remotely within the facility [30]. The wind turbines with control systems have been designed and simulated for the N44 H-MG, with a pending installation date.

In this paper, the design, implementation, and simulation of an H-MG Testing Facility are presented, outlining different elements within it required to make a functional MG test system. Chapter 2 highlights the architectural design of the AC/DC network, showcasing design elements of the building, DC/DC converters, energy storage, Statcoms, communication system and control systems. Chapter 3 illustrates the implemented system and installation process of the DC and AC elements within the H-MG facility. Chapter 4 presents the experimental results from the building and the two Statcoms, Elevare Energy and Power IQ. Chapter 5 presents primary, secondary and tertiary control simulation results based on the H-MG. Chapter 6 summarizes the main points presented and concludes the paper.

\section{Griffith Hybrid AC/DC MG Architecture Design}

The H-MG testing facility at Griffith University has been built to undertake testing of the impacts of Statcoms, energy storage, solar PV generation methods, wind turbines, and communication and control systems in a commercial environment and investigate energy management of the commercial H-MG.

\subsection{Design Consideration}

Extensive design considerations are taken when approaching the design of the H-MG testing facility. These considerations look into current and future applications where usability and reliability are key elements in prolonging the life expectancy of the installations. For this matter, high-quality and high-efficiency components are utilized to ensure project longevity. The initial design procedure separated the testing space into surrounding three topics for investigation sub-cast from the initial energy management target. These topics include:

- Investigation of solar PV topologies; solar power converters (DC/DC, DC/AC) and wind turbines

- Power conversion, control and energy storage management; via the use of static synchronous compensators

- Energy storage systems analysis with additional analysis on the impacts of PEVs 
These three topics determined the structure and monitoring of the testing facility to provide the best solution for energy management for current and future technologies. The design and installation procedure proved to be difficult; with numerous standard consultations and university specific installation requirements. The resulting flowchart of system build is presented in [37].

\subsection{System Architecture Design}

The design methodology utilized in the development of the H-MG is similar to that of the construction of a standard style MG, but where the addition of a DC bus is included. The system owns a common $A C$ bus which is set to $400 \mathrm{~V}$ low voltage according to the Australian standard. The $\mathrm{H}-\mathrm{MG}$ is connected to the utility grid and other $\mathrm{AC}$ form generation units (wind turbines) through the AC bus. Three single-phase Power IQ Statcoms construct a 200V low voltage DC bus. In this case, the power generation (both active power and reactive power) from each phase is controllable. A three-phase Elevare Statcom is also connected to the AC bus in order to achieve the three-phase power generation control. The DC voltage is realized by Elevare Statcom ranges from $500 \mathrm{~V}$ to $800 \mathrm{~V}$ which is determined by the state of charging of the battery. The overall design of $\mathrm{H}-\mathrm{MG}$ is visualized in Fig. 2.

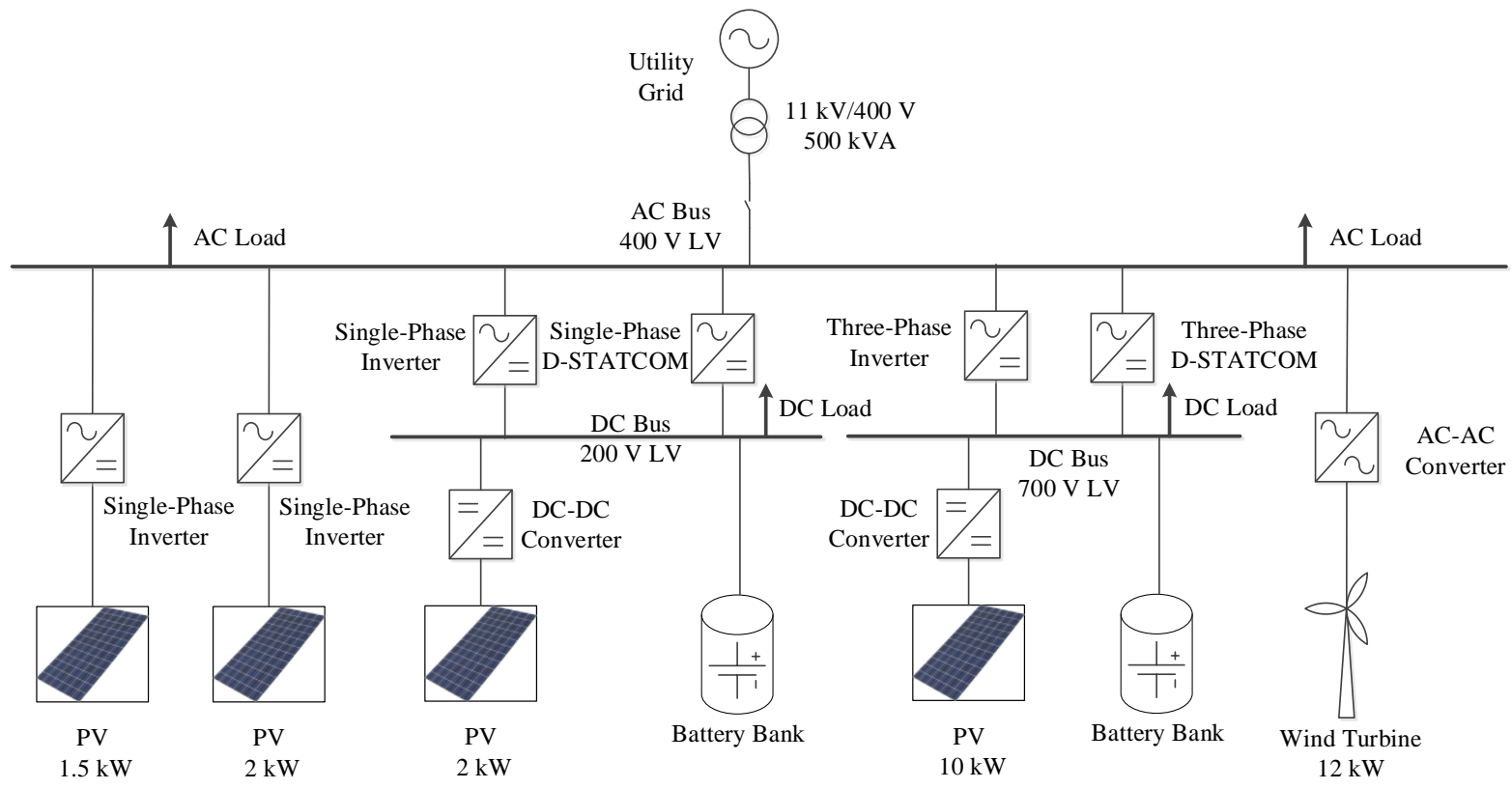

Fig. 2 N44 H-MG System Structure

\subsubsection{Griffith University N44 Building Load}

The power consumption in N44 fluctuates a lot due to the great number of labs and inductive load. Severe high demand peaks are paid especial attention in this system as they may cause additional financial charges. In addition, there is also enough space for PV section, energy storage units and testing equipment to be installed and expanded. Moreover, N44 is also near to vehicle to grid test building and community building which will be developed as other MGs in order to build a multi-MG system. Therefore, N44 building establishes a perfect location to build the hybrid MG testing facility. The local distribution network which N44 building is connected to and the internal N44 building network structure is illustrated in Fig. 3. 


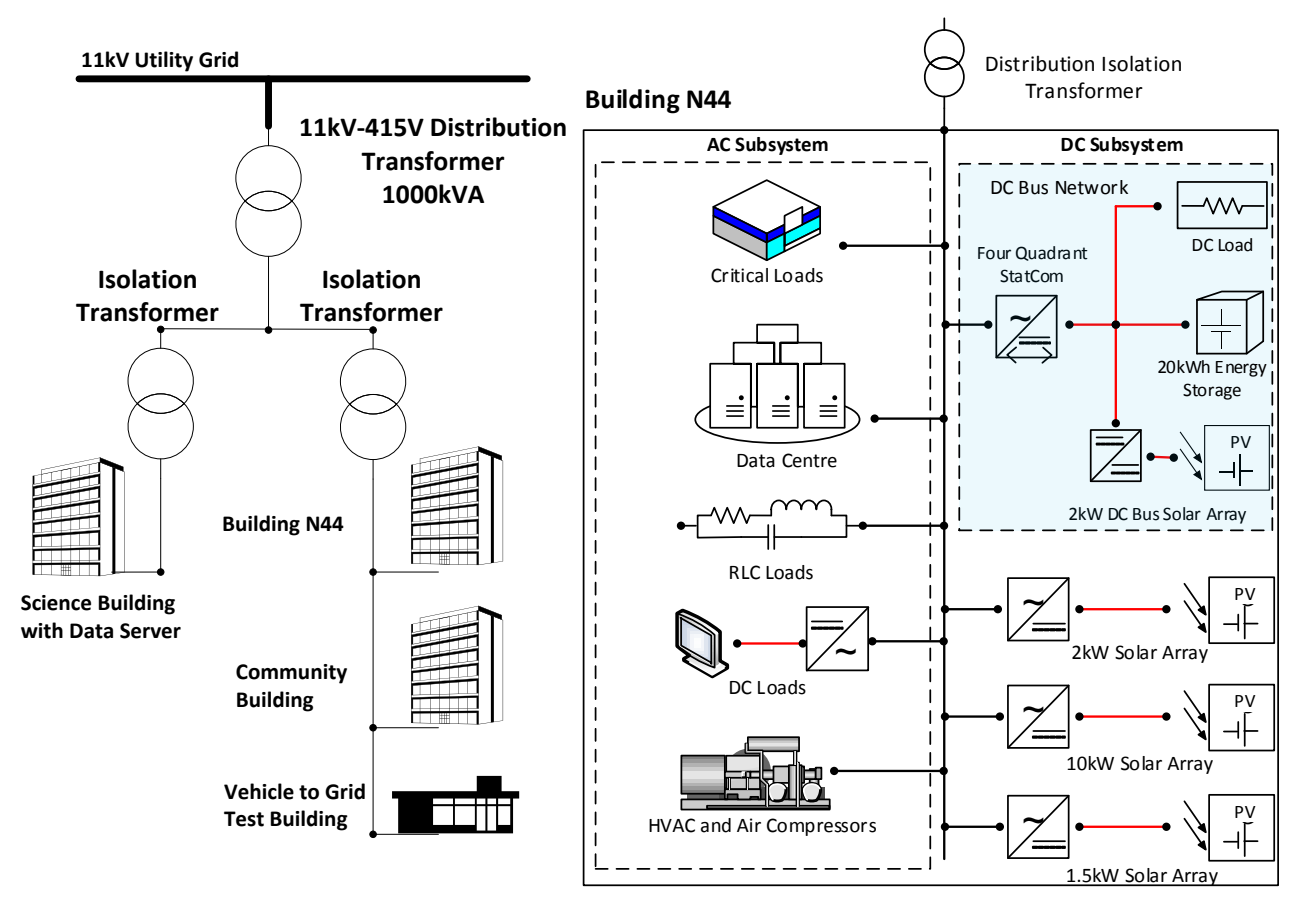

Fig. 3 N44 Local Distribution Network (left); N44 Building Network Structure (right)

The instantaneous perceived load on the network can be simply described as per equation (1), where the building loads and generation sources determine the overall load.

$$
P_{B}=\left(P_{\text {Mech }}+P_{\text {Live }}\right)-\left(P_{R E S}+P_{G E N}+P_{E S S}+P_{P F C}\right)
$$

where $P_{B}$ is the power in the building, $P_{M e c h}$ is the mechanical base load of the building, $P_{\text {Live }}$ represents the live load, $P_{R E S}$ and $P_{G E N}$ represent energy generation in the form of intermittent renewable energy systems and steady state generators, $P_{E S S}$ represents the implemented energy storage system, and $P_{P F C}$ is the power characteristics of the power factor correction devices.

As both real and reactive power contribute to the building load, each element within $P_{B}$ can be described as equation (2).

$$
P_{L i}=\frac{V I}{2} \cos (\theta)=\frac{1}{2} I^{2}|Z| \cos (\theta)
$$

Where; $P_{L i}$ represents the average power in a load element, $V$ and $I$ are peak amplitudes of voltage and current waveforms respectively, $\theta$ is the phase angle between $V$ and $I$, and $Z$ is the impedance of the load. By incorporating both real and reactive components, the apparent power illustrates the total load on the network from the building. This data has been collected and is presented as a characteristic curve Fig. 4. As can be noted, the yearly average building apparent power characteristic contains two peaks about $12 \mathrm{pm}$ and $4 \mathrm{pm}$ correlating with the live utilisation of the building. Timed loads can be seen switching on at 4:30am and 7:30am which correlate with mechanical loads such as compressors for compressed air, vacuum and the building air conditioning (HVAC) systems. Reductions in energy usage that are abrupt correlate with automatic network shutdown procedures for computers and secondary HVAC systems, typically observed about $7 \mathrm{pm}$ and $11 \mathrm{pm}$. The average static load for the building is 100kVA. 


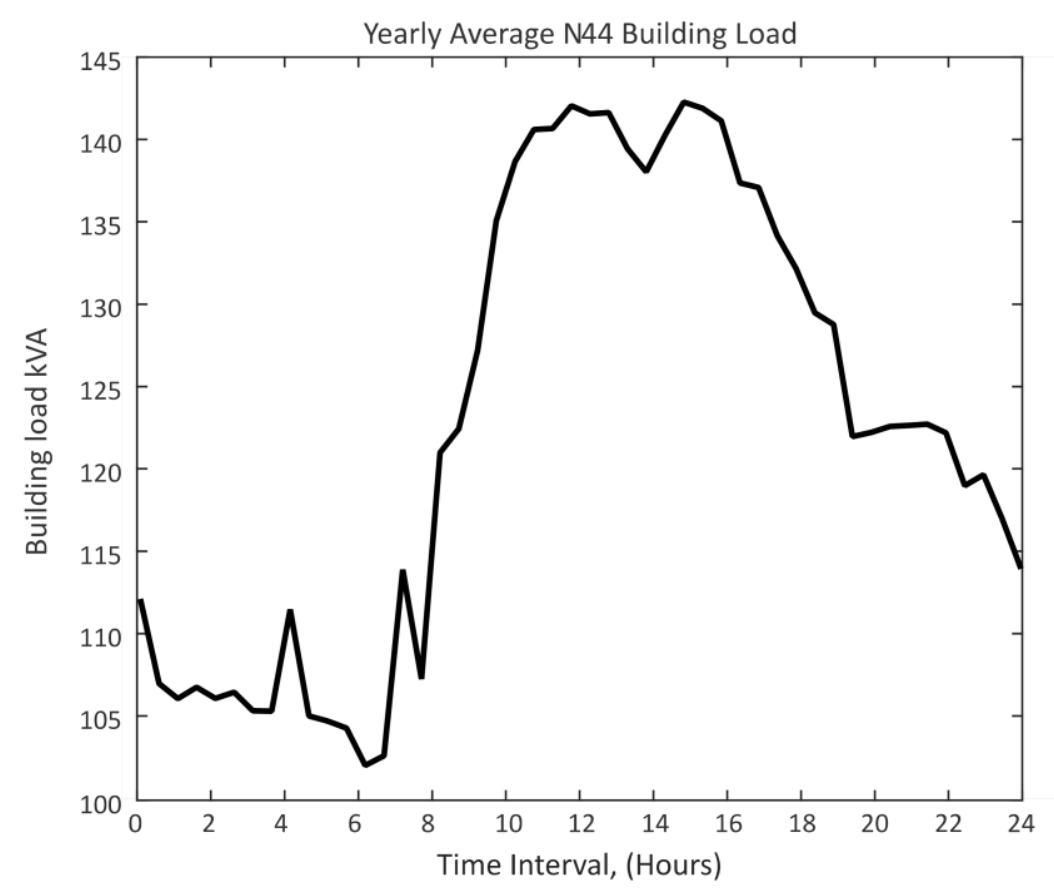

Fig. 4 Daily load for N44 Building as an average over a year

\subsubsection{Bus}

\subsubsection{Solar PV System}

The testing facility includes two $2 \mathrm{~kW}$ solar systems, one $10 \mathrm{~kW}$ solar system and a preexisting system of $1.5 \mathrm{~kW}$ installed. Together, there is a total capacity of the $15.5 \mathrm{~kW}$ peak of solar generation.

The structure of the two $2 \mathrm{~kW}$ systems consists of one configuration of a standard series installation and the other one as a panel-by-panel modifiable system. This interchangeability within configurations alongside a standard installation allows for a comparative analysis of different products available for the solar PV market. The primary analysis for the comparative $2 \mathrm{~kW}$ system is to determine the effectiveness of DC/DC converters on every panel in a parallel topology. This configuration forms a completely different architecture to what is currently utilized in the market.

\subsubsection{2. $D C / D C$ Converter}

The DC/DC converters create a stabilized voltage DC bus, which is capable of transferring power independently to the AC network. Utilizing DC/DC converters presents the ability to obtain a controllable DC bus; to where DC components such as batteries can be directly connected with minimum additional componentry.

The advanced one-stage PV solar energy storage configuration introduced in this project is attracting market interest. The schematic of the one-stage solar PV energy storage system is shown in Fig. 5. Each solar panel is equipped with an individual DC-DC converter, in which the converter regulates the voltage level to the required battery charging range of 336 to 470 V. The DC-DC converter also has an inbuilt Maximum Power Point Tracking (MPPT) function to obtain the maximum possible power of PV panels. Every solar panel unit is operating independently so that failure in one or more units does not affect the operation of the whole system. 


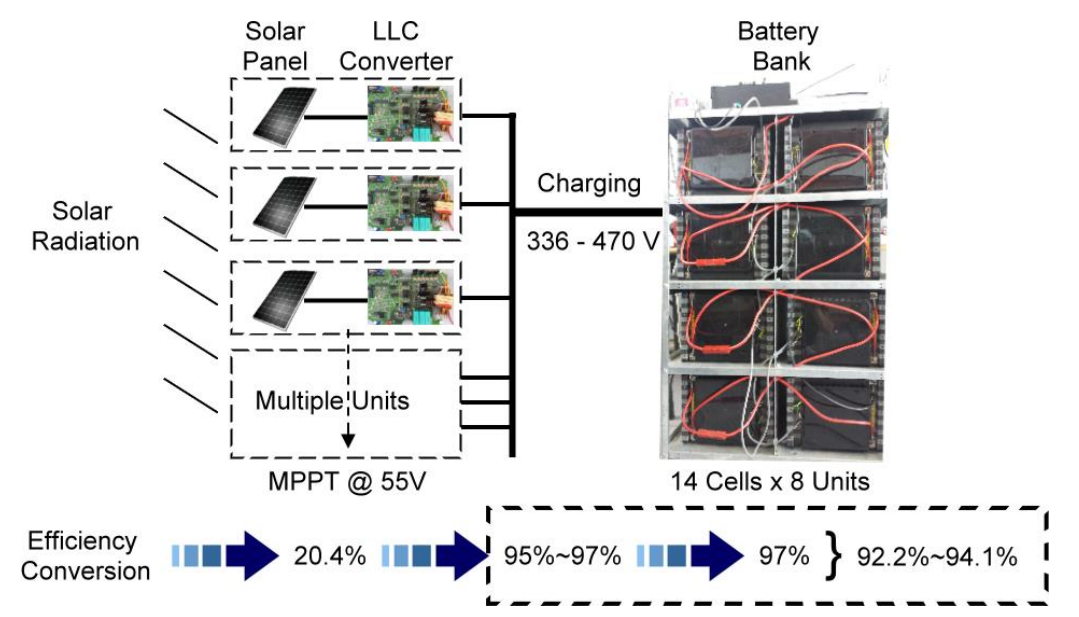

Fig. 5 Illustration of PV energy storage system configuration for single phase system

Meeting the Criteria for AC/DC MG Element

In order to realize the one-stage PV energy storage configuration and benefits from its structure, some requirements must be met by the utilized converter: (1) compact and inexpensive; (2) galvanic isolation; (3) high efficiency; (4) high voltage gain ratio; (5) broad voltage regulation range; and (6) light load operation. Therefore, LLC resonant type converters with the utilization of HF isolation transformers have been selected as satisfactory. To achieve soft-switching of Zero Voltage Switching (ZVS) or Zero Current Switching (ZCS) for the LLC converter, a resonant tank is required in the front end of the converter. In order to reduce the converter volume, the best solution is to integrate the resonant tank with the transformer [38].

\subsubsection{Battery Energy Storage}

The N44 H-MG installation has a capacity of 60 kilowatt-hours of Kokam ${ }^{\circledR}$ lithium-ion based batteries and 20 kilowatt-hours of Toshiba ${ }^{\circledR}$ lithium-titanate batteries. These batteries are configured into two strings of low and high voltage DC, based upon a single phase or three phase installation. The batteries are charged directly via the DC bus, where the DC/DC converters act as a voltage controlled charger for a battery bank. Each battery bank has an on-board battery management system (BMS) to prolong the battery life and ensure safe operating conditions for the lithium cells. Energy storage can be used for peak load shifting, peak demand management and providing uninterruptible power supply function. Since there is a possibility to connect Plug-in Electric Vehicle (PEV) to the MG system, it is necessary to test the PEV charging characteristics and Vehicle to Grid (V2G) function in order to keep the system stable. Therefore, the hybrid MG system chose the high-performance Kokam ${ }^{\circledR}$ Lithium-Ion Polymer batteries to solve such problems.

\subsubsection{Statcoms}

Griffith University in conjunction with Elevare Energy and Power IQ developed an advanced three-phase four-wire $30 \mathrm{kVA}$ Statcom and a single-phase $10 \mathrm{kVA}$ Statcom for the H-MG project. The schematic of the single phase Statcom is shown in Fig. 6 and was designed for application with DC bus voltage lower than $400 \mathrm{~V}$, as well as the power rating is less than 10 kVA. The single phase Statcom is capable with additional functions and benefits to both the utility and users. The single phase Statcom developed with Power IQ has an advanced three-cell Interleaved Current Transformer to maximize the system efficiency. Also, it is able to cope with the battery voltage range from $200 \mathrm{~V}$ to $600 \mathrm{~V}$ as well as the in-built intelligent battery charging and discharging functions. For application with power rating greater than 10 kVA, the three phase four wire Statcom developed with Elevare can be good use with the schematic shown in Fig.7. The three-phase Statcom is capable of operating with high 
voltage battery bank rated from DC $700 \mathrm{~V}$ to DC $1000 \mathrm{~V}$. Compared to the traditional products in the market, the switching devices of MOSFETs are chosen instead of the commonly used IGBT. The four-wire structure has better performance when dealing with three-phase imbalance situation compared to the traditional Statcom.

The three-phase Statcom can operate as a high rating single phase unit if required. The design of the unit allows power to be taken from one phase put into another phase to balance the phase loads. The units also act to balance the phase voltages thus removing negative sequence components. The Statcom is also capable of power conditioning for voltage, sags/swells, and harmonic absorption. The unit can be configured to maintain a set voltage by sourcing or sinking VARs in the first instance then $\mathrm{kW}$ - subject to availability of battery storage. Sags/swells from the customer installation or the grid supply can be completely eliminated. Interference harmonics can be absorbed in settable frequency bands. The Statcom does not attenuate distribution utility audio frequency load control signals and is capable of charging various battery types and chemistries. Furthermore, the Statcom is capable of limiting the power export to the grid as well as maintaining supply to the customer installation. It can also act as an Uninterruptable Power Supply (UPS) in conjunction with a storage battery.

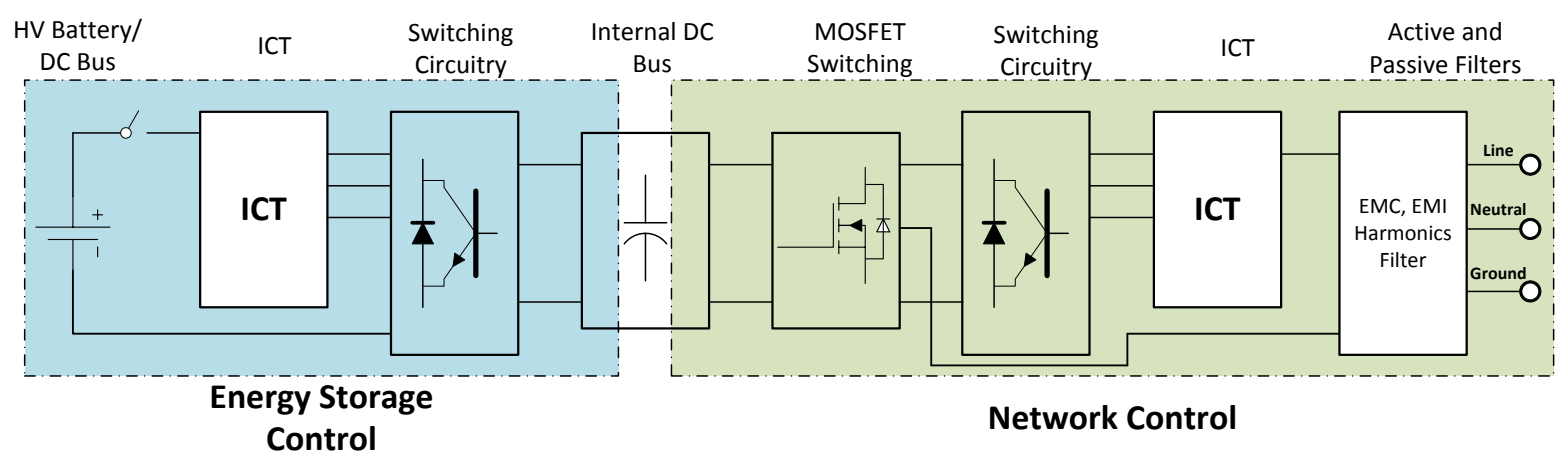

Fig. 6 Schematic of high voltage 10 kVA single-phase Statcom

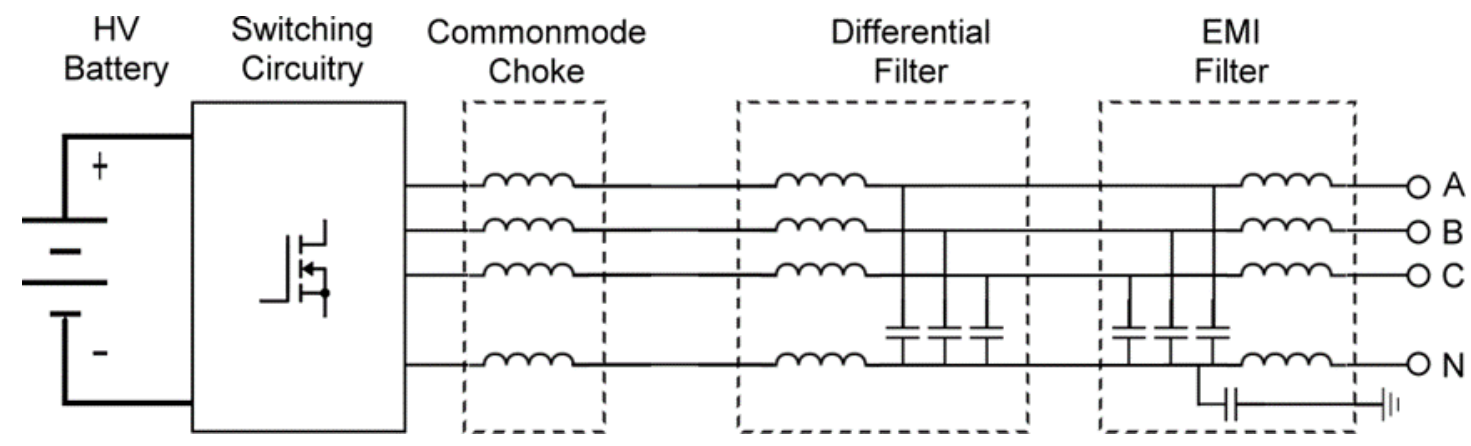

Fig. 7 Schematic of high voltage $30 \mathrm{kVA}$ three-phase four-wire Statcom Inverter

\subsubsection{AC Bus}

\subsubsection{Wind Turbine}

Four wind turbines with a total $12 \mathrm{~kW}$ maximum power output are designed to be installed in the Griffith hybrid MG. Two horizontal-axis wind turbines and two vertical-axis wind turbines are chosen according to the cost, rating power, cut-in speed and weight which are shown in Table I. Through choosing the different types, the wind turbines are suitable for research, teaching and also demonstration. Considering the wind direction, the turbine tower height, and the building structure, the wind turbines' location is at each corner of the rooftop on the N44 building as shown in Fig. 8. 
Table I. Wind Turbine Models

\begin{tabular}{cccccc} 
Axis & Brand & Model & Power Rating & Cut-in speed $(\mathrm{m} / \mathrm{s})$ & Weight $(\mathrm{kg})$ \\
\hline \multirow{2}{*}{ Horizontal } & Ampair & 600 & $0.7 \mathrm{~kW}$ & 3 & 16 \\
\cline { 2 - 6 } & Energy Ball & V200 & $2.25 \mathrm{~kW}$ & 3 & 90 \\
\hline \multirow{2}{*}{ Vertical } & UGE & VisonAIR3 & $1 \mathrm{~kW}$ & 3.5 & 470 \\
\cline { 2 - 6 } & TOYODA & TYD450-2000W & $2 \mathrm{~kW}$ & 2 & 109.1
\end{tabular}

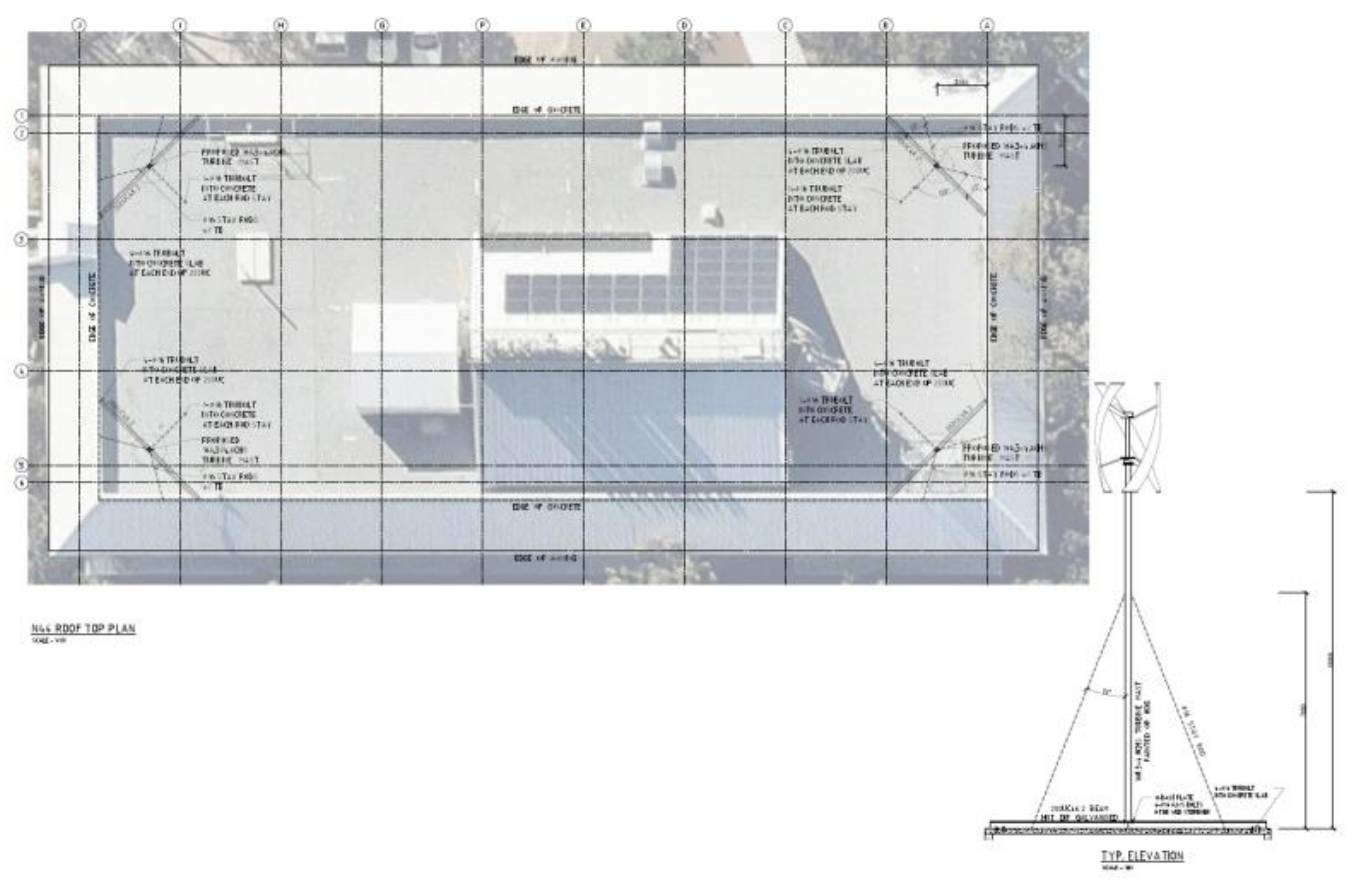

Fig. 8 Wind Turbine Location Design

\subsubsection{Inverters}

Since the MG has both $A C$ and DC buses, there is a necessity to convert DC power to AC power. In the context, proper inverters should be selected to achieve such function. In this system, SMA ${ }^{\circledR}$ transformer-less inverters are adopted. SMA ${ }^{\circledR}$ has a strong marketing around the world, and its inverters possess high efficiency and communication links. Unlike traditional transformer based inverters, the $\mathrm{SMA}^{\circledR}$ inverters use power electronics and highfrequency transformers (very small size) to convert power. The inverters implemented in this system are one SunnyBoy ${ }^{\circledR}$ TriPower $^{\circledR}$ 10000TL transformer-less and two SunnyBoy ${ }^{\circledR}$ 2100TL transformer-less inverters. The two 2100TL inverters ensure the solar PV panels to operate steadily without introducing any problematic uncertainties. In addition, through the SMA $^{\circledR}$ SunnyBoy ${ }^{\circledR}$ Web-box, all the parameters related to the inverters can be monitored.

\subsubsection{Control, Communication and Monitoring System}

The experimental MG requires a control and communication system to operate [29]. A proper communication system is required to measure variables on load and generation side, manage the protection system and facilitate control and management system operation. Running the communication system enables the control system to receive data, analyze the information and send commands to different devices within the MG. In this section, the design consideration of the communication, monitoring [30] and control system in different levels of primary, secondary and tertiary control is explained.

\subsubsection{Communication and Monitoring System}

Accurate monitoring of solar PV generation, conversion, and building loads are essential to create a meaningful system to compare and analyze the different aspects of the MG testing 
facility. Monitoring of the AC side of the facility is conducted via two/systems; the onboard on the inverter, industry standard EDMI MK10A power quality meters and an external portable data logging three-phase power quality analyzer independent of the other systems. DC monitoring is conducted via multiple stages, depending on the location of the facility. Some of the solar PV modules are monitored on a panel by panel basis via the DC/DC converters and a solar panel monitoring system; which also monitors temperature and solar irradiance. Solar irradiance is determined through two systems; a SMA Sunny Sensorbox ${ }^{\circledR}$ and a highprecision ambient light sensor coupled to a Raspberry $\mathrm{Pi}^{\circledR}$. The two sets of sensor data are compared against a neighboring building with a pyranometer and pyrheliometer to maintain accuracy. The $10 \mathrm{~kW}$ system's PV strings alongside the $2 \mathrm{~kW}$ interchangeable system have the capability of being monitored via an analog measuring device and RedLion ${ }^{\circledR}$ monitor. At the same location, digital logging handheld calibrated multimeters (Keysight ${ }^{\circledR}$ 1242B) can be utilized to further monitor the DC network with high accuracy and reliability. The implemented systems include multiple access points for measuring and monitoring the DC and AC network. This ensures an unbiased monitoring system to maintain system integrity. In this project, Modbus and CAN Bus protocols are mainly employed for the experimental MG communication system. In the cases that Modbus or CAN Bus are not available, HTTP TCP/IP is used for communication between installed devices. The overall communication and monitoring system is illustrated in Fig. 9.

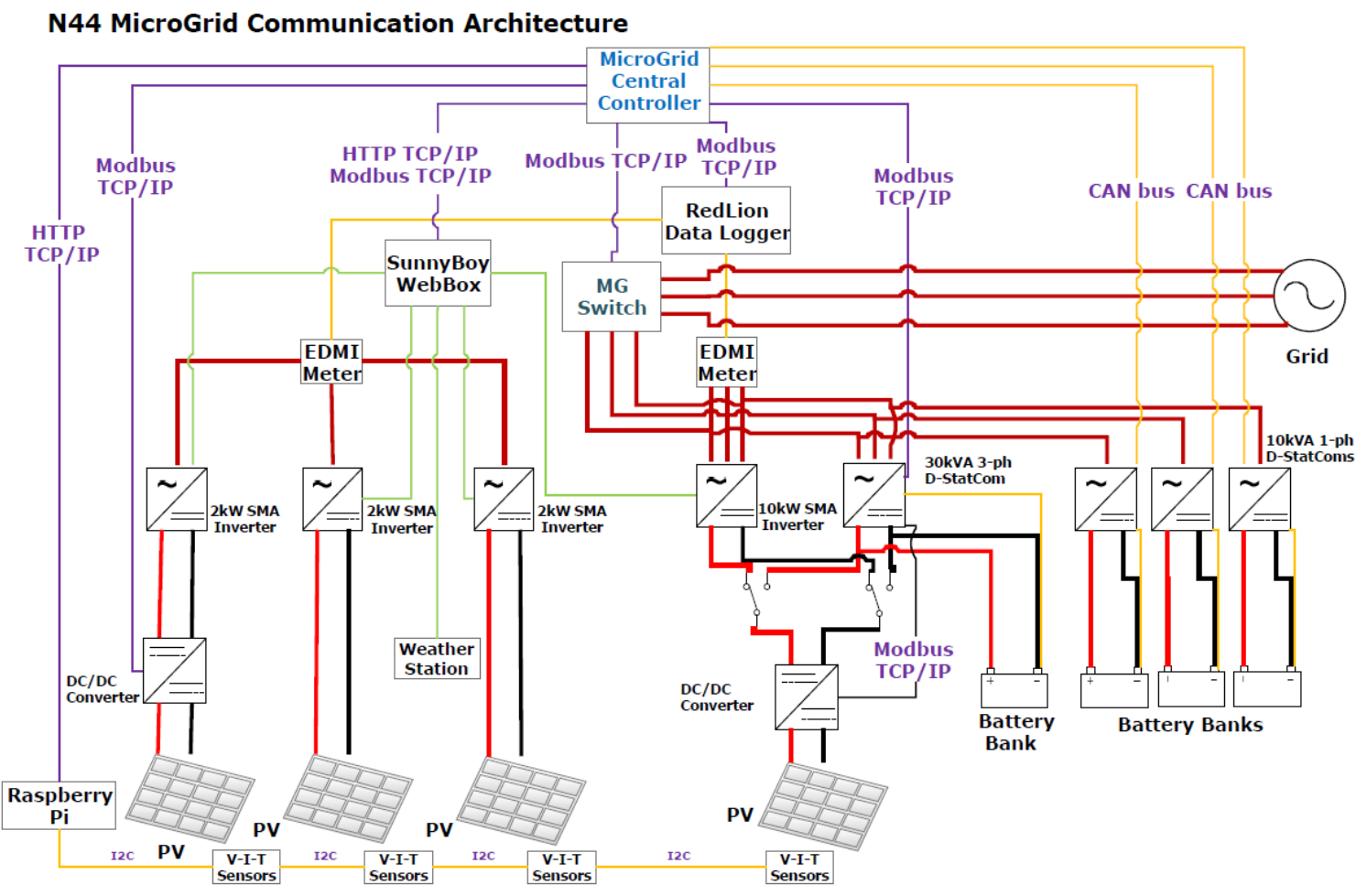

Fig. 9 N44 Experimental MG Communication Architecture

\subsubsection{Interlinking Inverter Controllers Design}

The DC/AC inverter utilized in the H-MG can only keep the system operating under gridconnected mode. Therefore, a proper inverter control strategy should be developed for the islanding case consideration. The control objectives of the inverter include two parts: guaranteeing the stability of the system's voltage and frequency; controlling the power generation of each DER unit. In the hybrid AC/DC MG system discussed in this paper, there are two distributed generation units (WT and PV with battery) connected to the AC bus. 


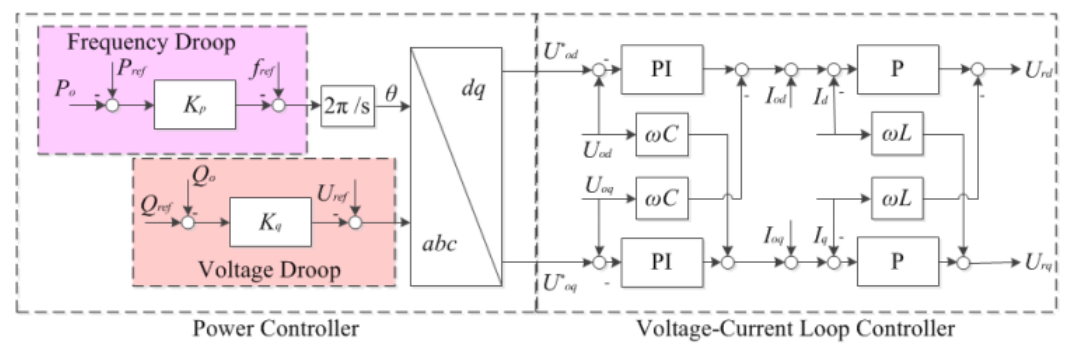

Fig. 10 Droop controller design

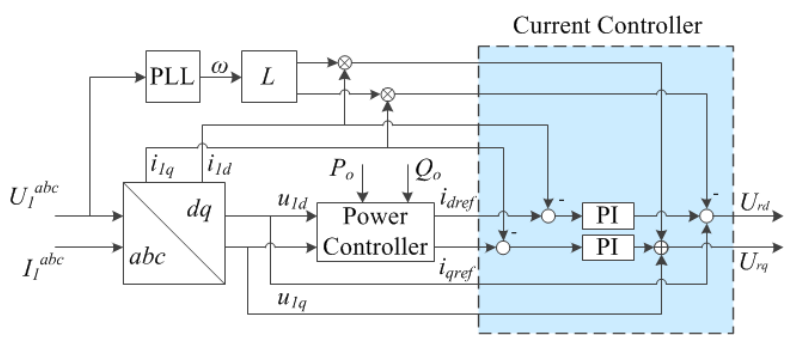

Fig. $11 \mathrm{PQ}$ controller design

A master-slave control mode is applied in the system according to the capacity allocation of the DER units. Droop control is selected as the master control strategy since it is able to keep the MG operating under both grid-connected mode and islanding mode. The slave generation unit adopts $\mathrm{PQ}$ control so that there is no need to concern about the voltage and frequency regulation. According to the basic principle of the droop control [39], the droop controller proposed in this paper (including a power controller and a voltage-current loop controller) is designed as in Fig. 10. PQ control is aiming at keeping the distributed generation output constant according to the reference active and reactive power. The $P Q$ controller design is shown in Fig. 11 [40].

\subsubsection{Energy Management System}

Energy Management System (EMS) plays an important role in generating the set points to dispatch power and meet the requirements of MG such as energy storage scheduling, peak shaving, and RES generation control. EMS receives the forecast information from RES and load and the market incentives from the grid and sets the optimized schedule of grid power consumption and energy storage system. EMS sets the energy storage scheduling system in a way that during high energy prices, battery discharges and while energy price is low, battery charges, illustrated in Fig. 12.

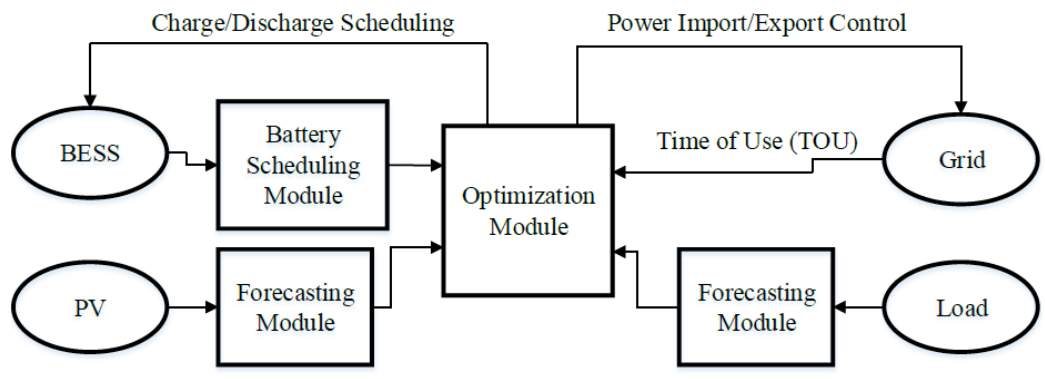

Fig. 12 Energy Management System

In this study, a rule-based EMS is developed for the experimental MG. The rule-based EMS determines the charge/discharge of energy storage system. The details of EMS are explained in [41]. Considering Time of Use (ToU) tariffs, load level and State of Charge (SOC) of battery, EMS decides during one day when the best time to charge and discharge 
is. The peak shaving algorithm provides maximum benefits of energy storage scheduling. The discharge algorithm follows three steps as mentioned in [41]:

Step 1: The scheduling system sets the discharge level at the highest rate;

Step 2: The discharge peak is ideal if the peak reduction during peak period causes the new peak to be the equal in the whole peak period;

Step 3: If discharge peak is not ideal, the discharge level would be reduced step by step to a level that battery has enough capacity to create the peak which is the same during the peak period. The overall algorithm of EMS is shown in Fig. 13.

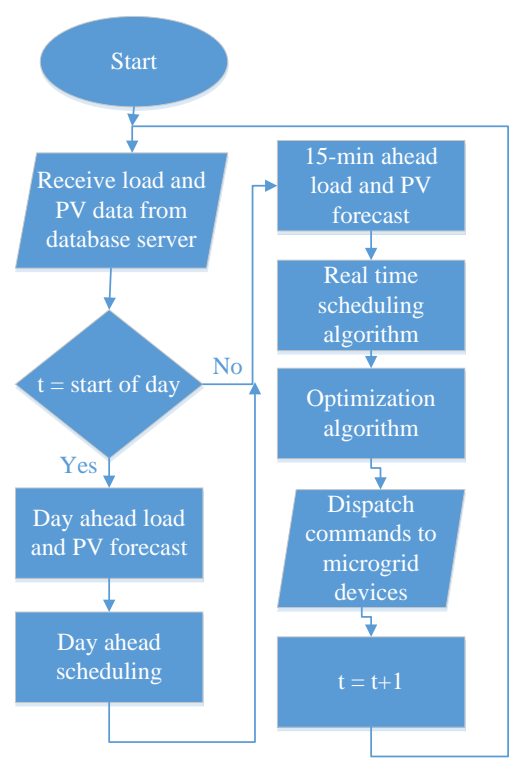

Fig. 13 EMS algorithm

\subsubsection{Forecasting System}

Forecasting system as a part of EMS decreases the level of uncertainty in the system. The forecasting system predicts PV generation and load consumption and deploys the information to the optimization system. In order to achieve a more accurate prediction of PV generation and load profiles, an expert system is developed in [42] which is the basis for the system in this study. The predicted information is utilized to set the initial schedule for the next day. The load forecast model is adapted for a commercial load profile. Following the model in [35], employing autoregressive moving average (ARMA) for average load forecast model, the model is:

$$
\hat{y}_{t}=\beta_{0}+\sum_{i=1}^{n} \beta_{i} y_{t-i}+\hat{\varepsilon}_{t}+\varepsilon_{t}
$$

where $y_{t}$ is load at time $t, \hat{y}_{t}$ is the load forecast, $\beta_{0}$ is the y-intercept and $\beta_{i}$ is the coefficient for time lag i. There are $\mathrm{n}$ number of time lags and $\varepsilon_{t}$ is the forecast error and $\hat{\varepsilon}_{t}$ is the error forecast for time $t$. The first step after forecasting the peak load is to forecast the load profile $L P F_{d, t}$ of the current day. The next step is the manipulation of $L P F_{d, t}$ to adjust it to match the peak load forecast and the final step to forecast the current day load profile is to add the historical error forecast to the load profile forecast as it is depicted in (4):

$$
L \widehat{P F}_{d, t}=L \widehat{P F}_{d, t}+\hat{\varepsilon}_{d, t}, \quad \text { for } 1 \leq t \leq 96
$$

where $t$ illustrates the time steps in one day forecast period and is equal to 15 minutes. 


\section{Implementation of Hybrid AC/DC MG}

After the design process of the Hybrid AC/DC MG, the next step is to implement and install hardware and software to be able to run various testing scenarios to improve the functionality of $M G$ at the component level and system level. The experimental Hybrid AC/DC MG implementation consists of three main sectors: DC section, AC section, and communication and Monitoring.

\subsection{Bus}

\subsubsection{Solar PV System}

According to the design procedure, solar PV and the wind are the main sources of energy in this project. Different technologies of solar modules are installed on the roof of the N44 building at Griffith University to investigate the performance of PV panels and also different parallel and series combinations of PV panels for further research on the DC bus performance in the experimental hybrid MG. Fig. 14 depicts the installed PV panels for N44 AC/DC MG.

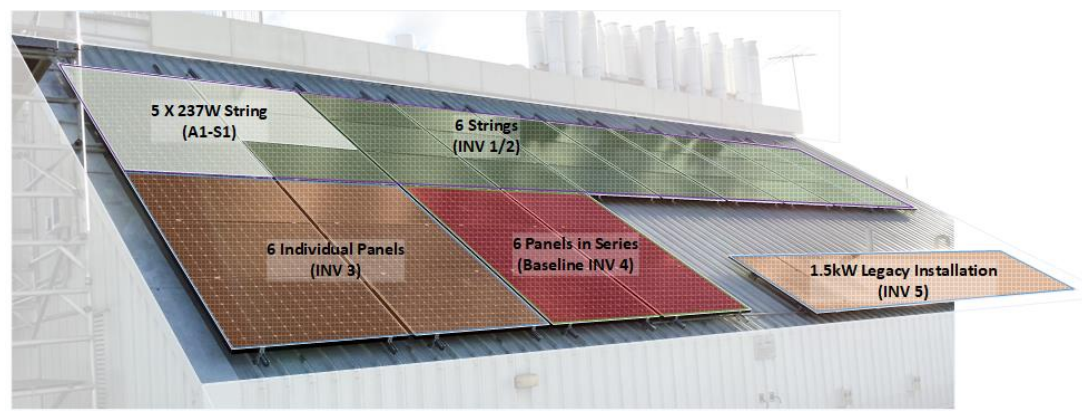

Fig. 14 N44 MG Solar Test Configurations

Location R contains 30 SunPower ${ }^{\circledR}$ E20 series $327 \mathrm{~W}$ solar modules. These modules are divided into six strings of 5 modules per string. This combination is necessary for interchangeability between the different inverter and Statcom technologies. Location $G$ contains six SunPower ${ }^{\circledR}$ E20 series $327 \mathrm{~W}$ modules with connection options at the marshaling box. The connections from each module are brought back to the marshaling box to enable testing of $\mathrm{DC} / \mathrm{DC}$ converter and inverter technologies. Location $\mathrm{B}$ contains six SunPower ${ }^{\circledR}$ E20 series $327 \mathrm{~W}$ modules with a standard series connection. These modules serve as the base case for the SMGTF. Location $Y$ contains 10 Kyocera solar modules with a combined power rating of $1.5 \mathrm{~kW}$. This system is an earlier installation from 2010.

\subsubsection{DC/DC Converter}

$D C / D C$ converters employed in the experimental MG, improve the efficiency of the system. Implementation of the converters facilitates the efficiency testing in the MG, shading analysis and DC bus voltage level control. Installation of DC/DC converters brings a higher efficiency charge and discharge of the battery. Fig. 15 illustrates the enclosure containing DC/DC converters installed at the experimental MG. 

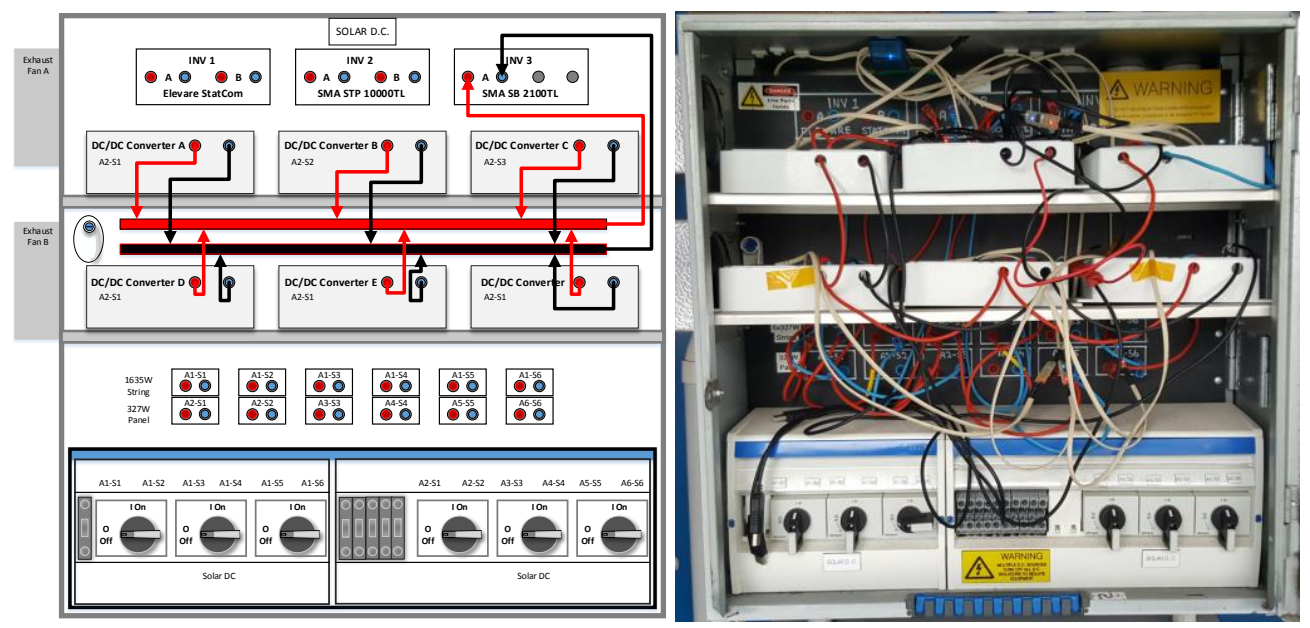

Fig. 15 Marshalling enclosure with basic DC/DC converter configuration

\subsubsection{Battery Energy Storage}

The other component of experimental MG on the DC side is Battery Energy Storage. Two battery packs are employed in this testing facility; Kokam ${ }^{\circledR}$ and Toshiba. Batteries are connected to the DC bus and are charged or discharged through either PV or grid. The installed battery packes are indicated in the Fig. 16 .

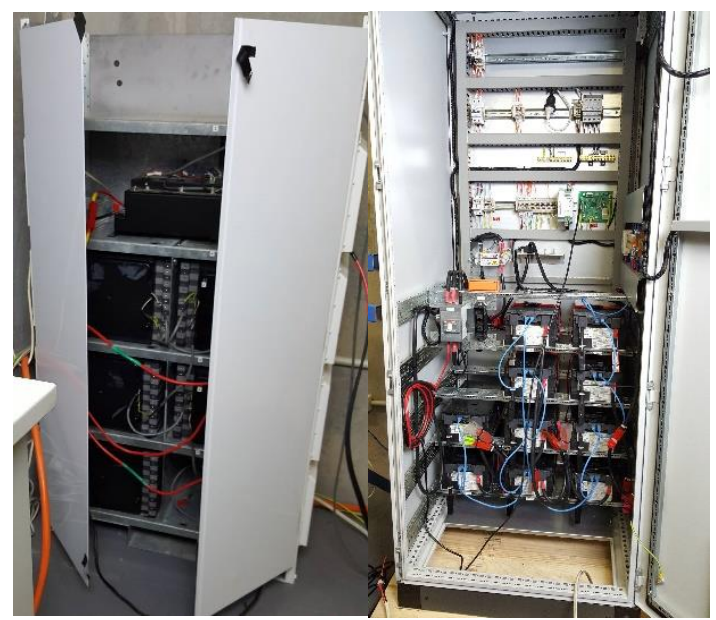

Fig. 16 Battery Energy Storage Systems: Kokam ${ }^{\circledR} 60 \mathrm{kWh}$ (left); Toshiba 20kWh (right)

\subsubsection{Power IQ Single-phase 10 KVA Statcom}

In the Hybrid AC/DC MG, Statcom connects DC bus to the AC bus. Three single-phase Power IQ Statcoms are installed in the experimental MG to test their performance as well as investigating their influence on the MG. Their performance is compared to conventional inverters in the MG. The installed three Statcoms and the Statcom itself can be seen in Fig. 17. 

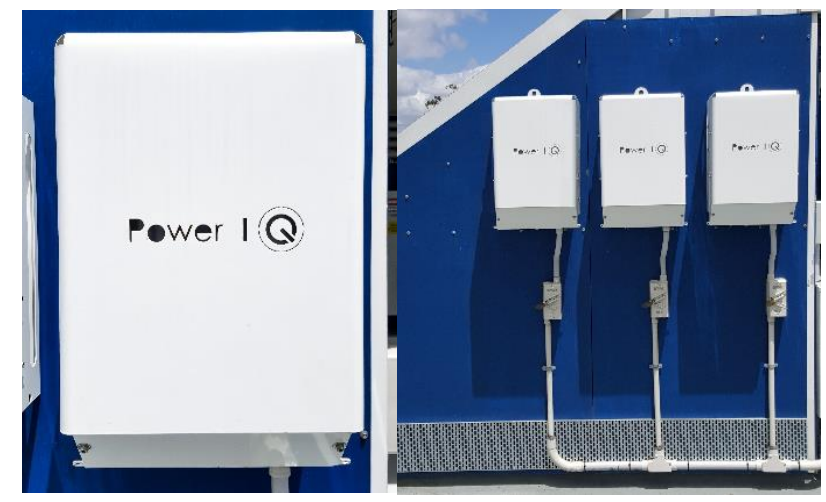

Fig. 17 Power IQ 10kVA Single-phase Four-Quadrant Statcom

\subsubsection{Elevare Three-phase 30 KVA Statcom}

Elevare three-phase Statcom is employed in the experimental MG to make a study on the performance of three-phase and single-phase Statcoms. The three-phase Statcom is connected to the DC bus to charge and discharge the battery and to the AC side to control the reactive power. The control system of the Statcoms modifiable which brings more options for testing and comparison in the testing facility. The three-phase Elevare Statcom is shown in Fig. 18.

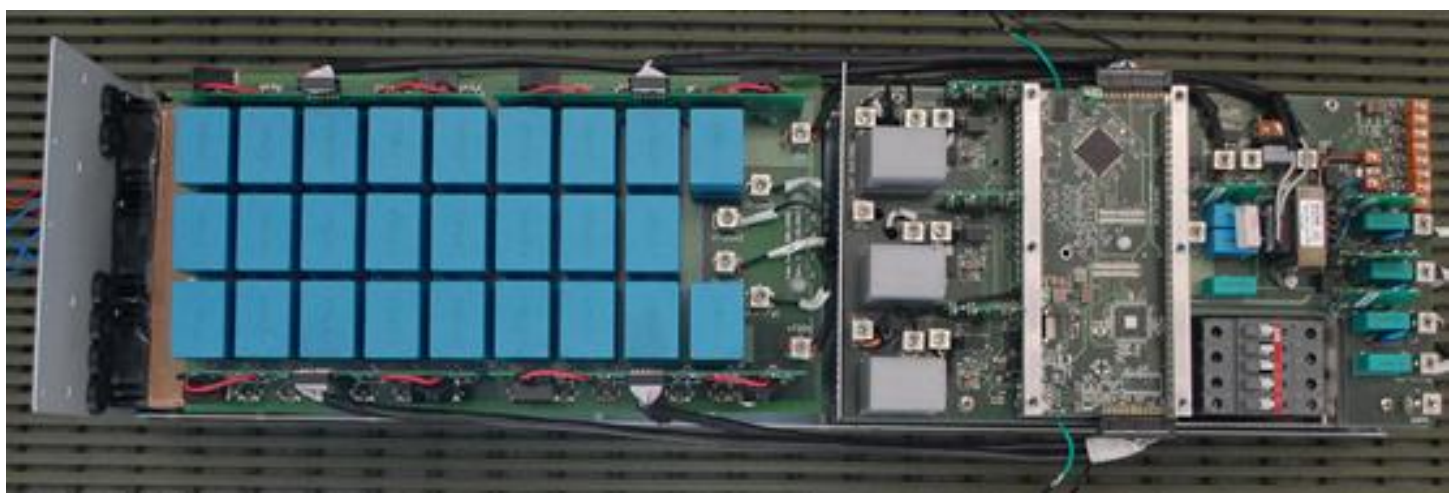

Fig. 18 Elevare 30 KVA Three-phase Statcom

\subsection{AC Bus}

The $A C$ side of the Hybrid AC/DC MG is the connection of the inverters and Statcoms to the grid. The conventional SMA inverters are installed in this experimental MG as a reference to compare to the Statcoms. In Fig. 19, the installation of AC bus, communication and monitoring sections is illustrated.

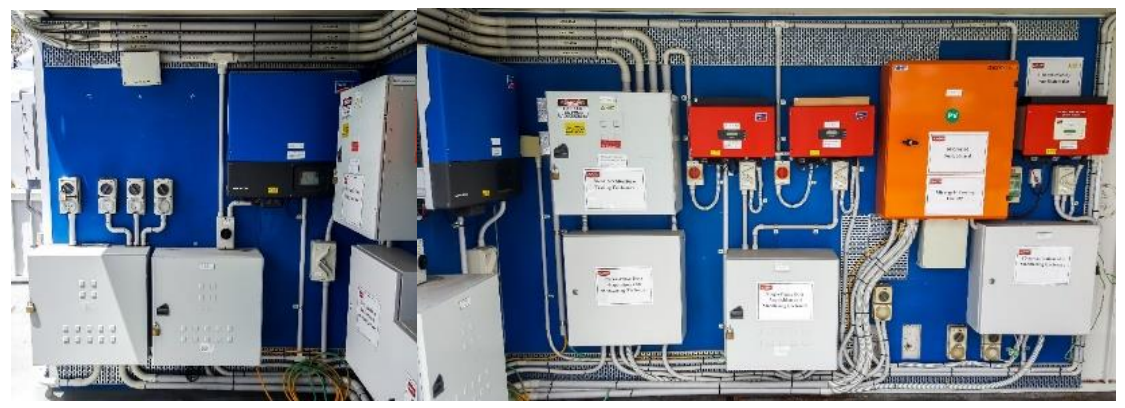

Fig. 19 N44 MG AC side, Control, and Communication Station 


\subsection{Communication and Monitoring System}

As an essential part of MG, a communication and control system is implemented in order to receive data from devices and send commands back to the components in MG. The control and communication server is developed in Python programming language. Pymodbus library is incorporated into the MG as a full Modbus protocol implementation.

In the control server, a data acquisition and monitoring system have been utilized to serve the received data to the website and log it to the MySQL database. The data acquisition system connects to the devices and polls every 10 seconds. Then, the collected data is streamed to the website to observe the data and logged in MySQL database [30].

The experimental MG communication and monitoring system comprises of various measurement and data logging methods including SMA SunnyBoy ${ }^{\circledR}$ WebBox, RedLion ${ }^{\circledR}$ data logger, Raspberry $\mathrm{Pi}$, Statcom Modbus interface, power meters, voltage, current, and temperature sensors, found in Fig. 20. To access the data parameters of SMA inverters, SMA utilizes SunnyBoy ${ }^{\circledR}$ WebBox for data acquisition. SunnyBoy ${ }^{\circledR}$ WebBox transmits data to inverters via Modbus RS485 and HTTP TCP/IP.

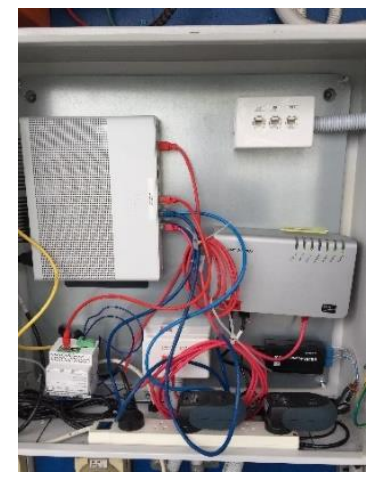

Fig. 20 SMA SunnyBoy ${ }^{\circledR}$ WebBox, Schneider Switch Communication, and Cisco Internet Router

RedLion $^{\circledR}$ data logger is a communication and control platform as a master module which mainly works as a gateway and gathers data from power meters and sends them to the control server via Modbus TCP/IP, Fig. 21. Voltage, Current and temperature sensors are installed to monitor the temperature of devices inside the cabinets and solar panels and voltage and current of each solar panel. The sensors are connected to each other via I2C bus and a Raspberry Pi connects the sensors to the control server. Three-phase EDMI power meters are installed to monitor real-time data of inverters and Statcom in MG. Power meters send the information to the data logger via Modbus RS485.
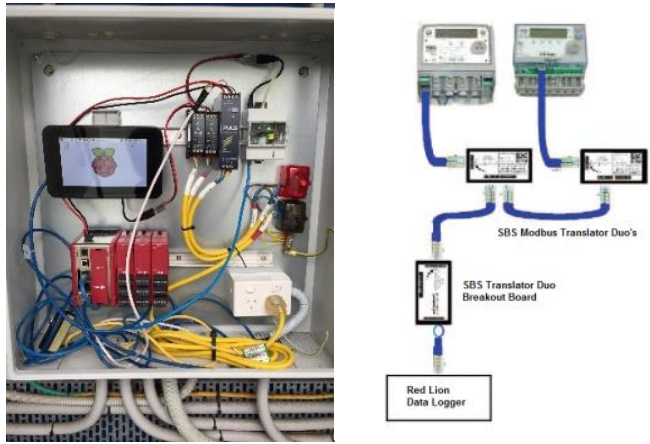

Fig. 21 Monitoring System Components, RedLion ${ }^{\circledR}$ Data Logger, Raspberry Pi and EDMI ${ }^{\circledR}$ Meters [30]

The main Schneider switch is installed as MG protection device and provides local and remote access to send commands to switch to turn it on and off for islanding mode 
transition, Fig. 22. The switch has a power monitoring unit which provides real time information of main electrical values and sends the data via a Modbus interface module.

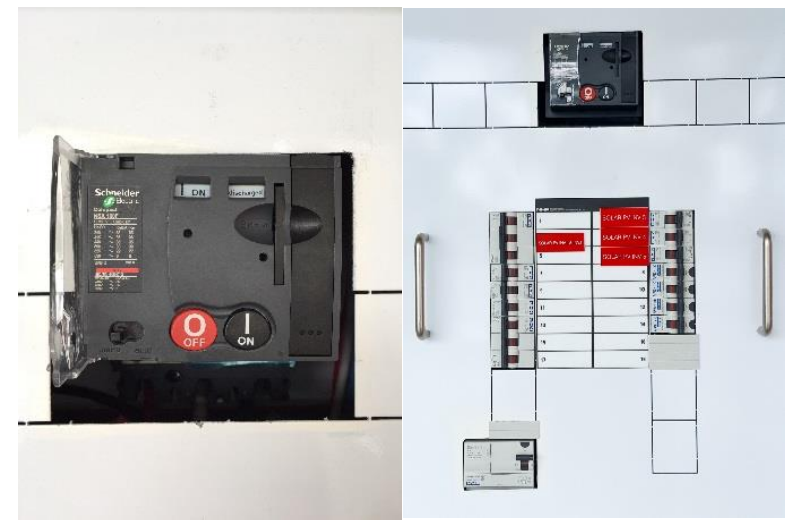

Fig. 22 N44 MG Switch Board including Schnider Smart Mains Switch

\section{AC/DC MG Testing Facility Performance and Results}

\subsection{Building Load and PV Solar Results}

The N44 building load in the experimental MG is a commercial load. Commercial loads tend to peak in the middle of the day with either one or two peaks, differing from residential loads, as residential loads tend to have two distinct peaks; one in the morning and the other in the evening [43]. As solar PV generates energy during the day with a peak nearing the middle of the day, a direct energy consumption and production correlation can be noted. This correlation has the ability to reduce the peak demand of a commercial load, consequently having the ability to decrease the amount of peak demand energy purchased from the grid.
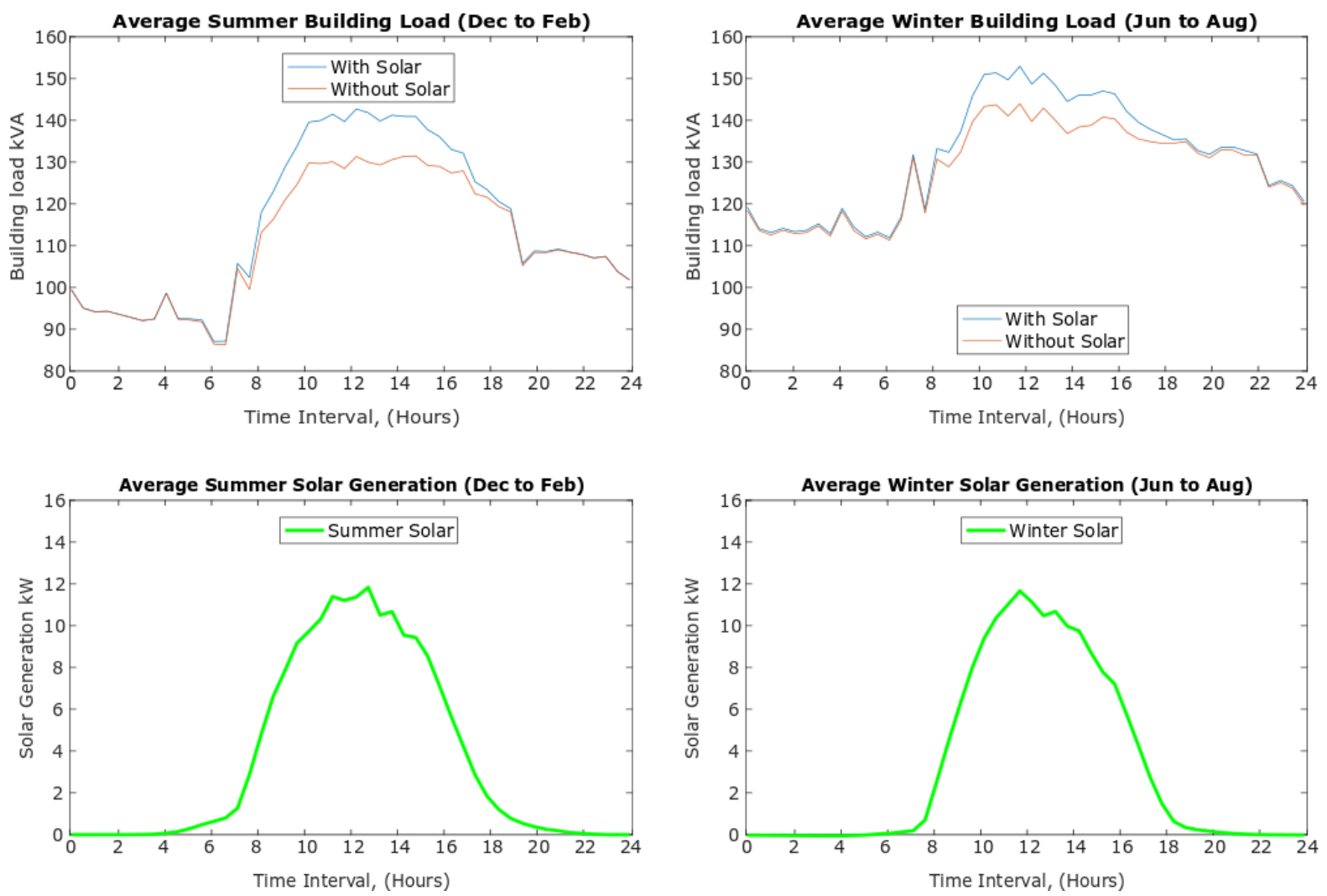

Fig. 23 N44 Daily Load, Solar Generation, and Perceived Load during Summer Months (December to February), (left); Winter Months (June to August), (right) 
A clear benefit in load consumption reduction can be seen in Fig. 23, where with the implementation of solar the summer and winter load characteristic is reduced. The energy reduction in summer is more substantial than in winter; partially due to the fixed position of the solar panels, but predominantly due to the increased heating element load during the winter months. As the location of the N44 H-MG is in Brisbane Australia, there is only a slight difference between solar production between summer and winter seasons. In summer months, solar energy has the potential to substantially reduce the peak demand, from $131 \mathrm{~kW}$ to $122 \mathrm{~kW}$, and reduced the overall daily energy by $96 \mathrm{kWh}$. In winter months, a reduction of the energy profile of $146 \mathrm{~kW}$ to $137 \mathrm{~kW}$ can be achieved, along with an energy consumption reduction of $93 \mathrm{kWh}$.

\subsection{Bus Results}

The DC bus at the N44 H-MG relies on the implemented energy storage system maintaining a DC bus voltage. When DC/DC converters from solar PV are connected to the DC bus, the $\mathrm{DC} / \mathrm{DC}$ converters determine the charge state of the $\mathrm{DC}$ bus via the $\mathrm{DC}$ bus voltage. As the $D C$ bus is reliant on the Kokam ${ }^{\circledR}$ lithium battery energy storage to maintain the DC bus, the State of Charge (SOC) is easily determined based upon the total cell voltage. When the $\mathrm{DC} / \mathrm{DC}$ converters determine the SOC is below a given threshold, they collectively raise the output voltage to allow current to flow into the energy storage system. This approach for raising the DC bus voltage in accordance with energy storage SOC voltage is presented in Fig. 24. The charging characteristics are indicative of a typical intermittent charging cycle from solar PV with the DC/DC converters performing as expected, tracking the PV curve. The total energy transferred from the DC/DC converters through the charging session increased the BESS voltage from $426.4 \mathrm{~V}$ to $427.3 \mathrm{~V}$ indicating a successful direct charging cycle. The solar PV conversion and MPPT by the DC/DC converter was also seen to be successful with an average conversation efficiency of $93 \%$ while the power range of the solar panels varied from $30 \%$ to $95 \%$ of the rated PV output. The charging voltage and subsequent recovery voltage of the BESS can also be observed in the teste case, where the voltage state of the ESS follows the characteristic in charging power and increases the base voltage as energy is transferred into the battery. 
Fig. $24 \mathrm{DC} / \mathrm{DC}$ converter performance on the DC bus from solar generation of 4 panels

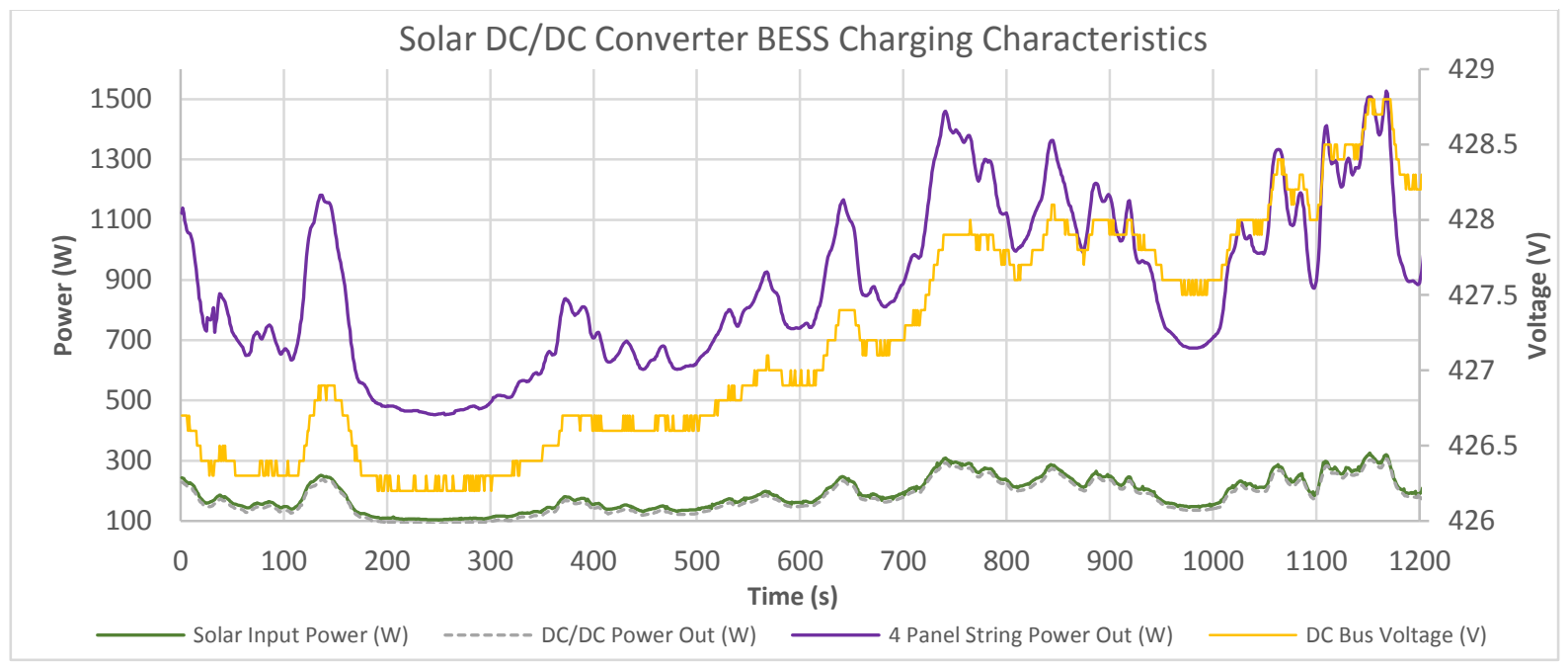

\subsection{Statcom Battery Charging Results}

The two Statcom units have been recently installed and tested in discharging mode with their respective battery banks, the Toshiba Lithium Titanate battery bank with the Power IQ 10kVA single phase Statcom and the Kokam ${ }^{\circledR}$ Lithium-ion battery with the 30kVA Elevare Energy three-phase four-wire Statcom. Discharging the energy storage with the Statcoms provides useful insight into the different battery bank performance, along with the base converter performance as the Statcoms provide the link between the AC and DC bus within the H-MG. 


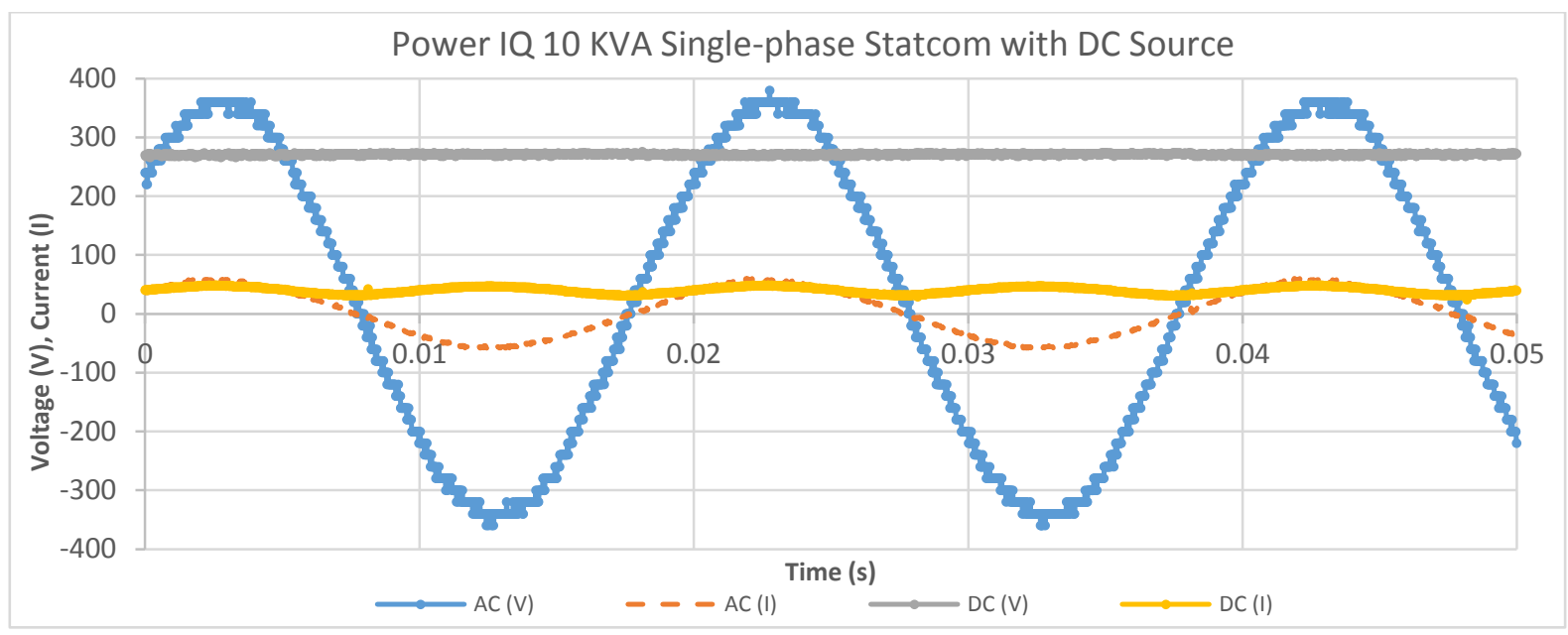

Fig. 25 Power IQ 10 KVA single-phase Statcom DC and AC side performance with Toshiba batteries

When tested with $20 \mathrm{kWh}$ of Toshiba lithium titanate batteries, the Power IQ 10kVA Statcom and the Toshiba batteries performed as expected with an output of performance shown in Fig. 25. The Statcom was discharging $20 \mathrm{kWh}$ of the energy storage at $10 \mathrm{~kW}$. The cycle analysis shows the voltage fluctuation between cycles was minimal and the sinusoidal waveform for both current and voltage from the Statcom are clear and concise.

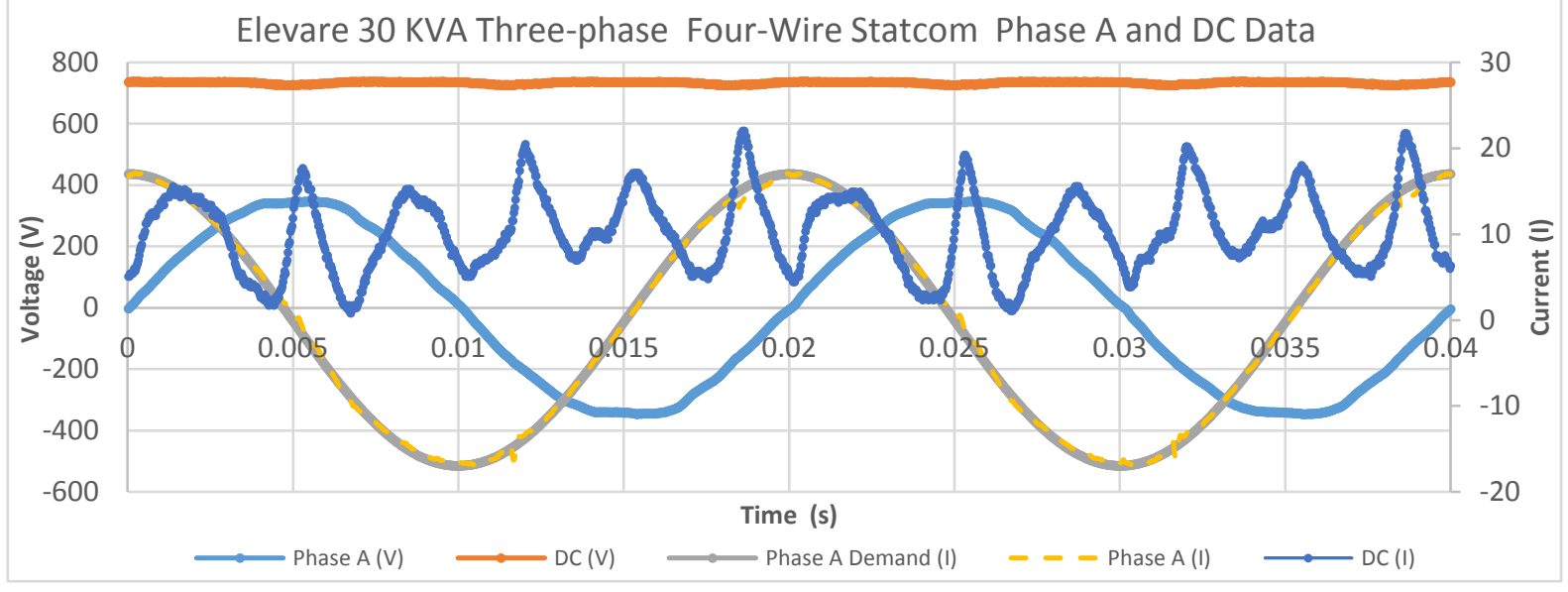

Fig. 26 Elevare 30 KVA Three-phase Statcom DC and AC side performance with Kokam ${ }^{\circledR}$ batteries

The Elevare Energy 30kVA three-phase four-wire Statcom was connected to 60kWh of $\mathrm{Kokam}^{\circledR}$ lithium energy storage, drawing a power of $10 \mathrm{~kW}$ across the three phases. The characteristic curve for phase $A$, along with the Kokam ${ }^{\circledR}$ battery performance is shown in Fig. 26. It can be noted that the DC current fluctuations are due to the three phases, two of which are absent in the diagram. Even at low power, the three-phase Statcom performed well within its acceptable bounds as did the Kokam ${ }^{\circledR}$ energy storage.

\section{Simulation of H-MG Testing Facility Control and Management Systems}

Before implementing different components in the Hybrid Experimental AC/DC MG, design elements require thorough simulation. This ensures reliable implementation of new algorithms and physical elements. In this project, the control system, the islanding mode transition and wind turbine integration are investigated.

\subsection{Simulation Model Structure}


The simulation model structure built in this paper is mainly on the basis of the real hybrid AC/DC MG system configuration developed on Nathan Campus, Griffith University, Australia, which is shown in Fig. 27. The system consists of low voltage distribution systems including distributed generation (DG) units. The complete simulation model comprises of two parts: a master generation part including PV and battery; a slave generation part contains the wind turbine generation system. The AC load is connected to the AC bus to simulate the real commercial building load.

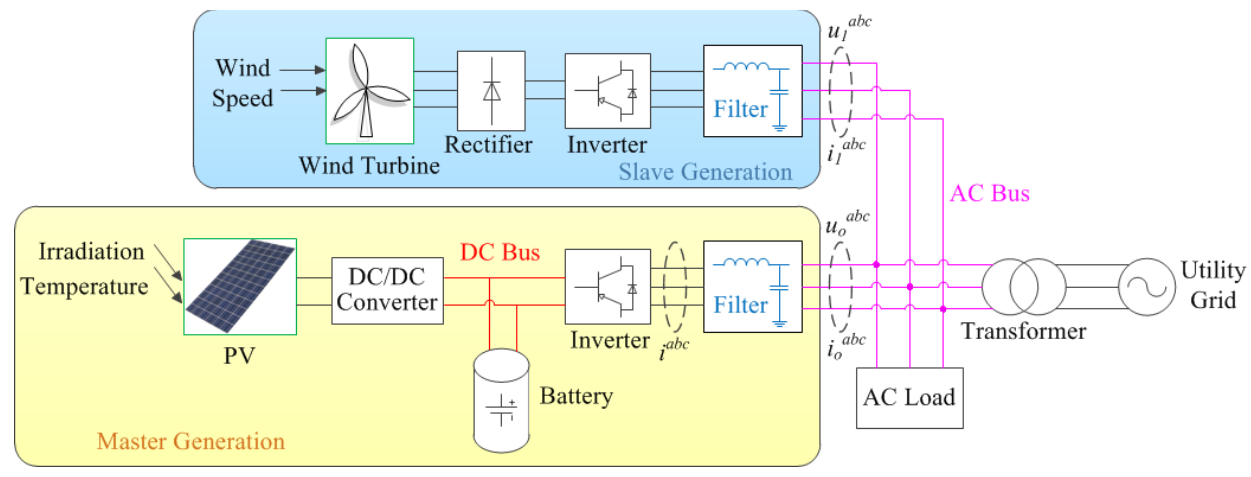

Fig. 27 Simulation model of the hybrid MG

In this section, simulations are carried out to demonstrate the operation performance of the hybrid MG system. The load data is chosen from the customer building N44 on Griffith University Nathan Campus during one random ordinary day. The 24-hour data is turned into $5.7 \mathrm{~s}$ in the simulation (from 1.3s to $7 \mathrm{~s}$ ). The DC bus is set as $500 \mathrm{~V}$ and the common AC bus RMS voltage is $400 \mathrm{~V}$. The rated frequency of the system is $50 \mathrm{~Hz}$. The MG output power is set at $85 \mathrm{~kW}$ including $75 \mathrm{~kW}$ from the master generation unit and $10 \mathrm{~kW}$ from the slave generation unit. The reference power set is chosen according to the capacity of the actual devices. An energy saving performance of the hybrid MG system is shown in Fig. 28.

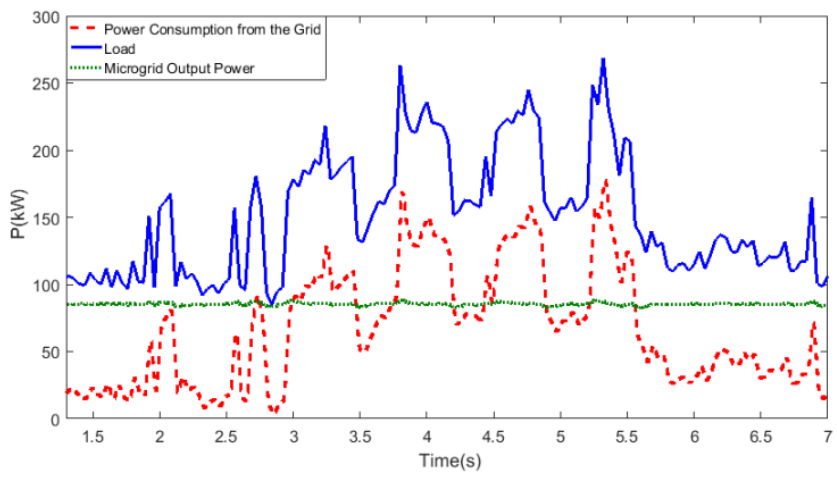

Fig. 28 Active power allocation of each element

Usually, the system's frequency and voltage are the indexes to estimate the performance of a power system. Under grid-connected mode, since the MG has the support from the utility grid, the frequency and the voltage from the point of the common coupling are both stable which can be seen in Fig. 29. However, since the capacity of the MG is not enough, the MG cannot maintain the frequency and voltage under islanding mode due to the drastic changes in load. Therefore, the simulation only covers the constant load case for the MG under islanding mode. The MG could achieve the best performance when matching the load. Such performances are shown in Fig. 30 , in which the load is set as $85 \mathrm{~kW} / 54 \mathrm{kVar}$ from a random point of the actual load. 


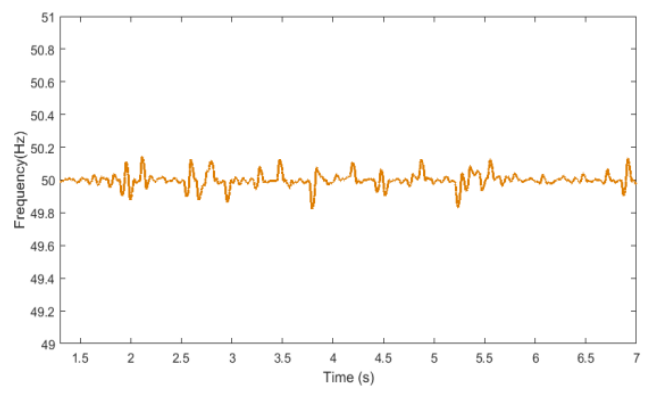

(a) Frequency

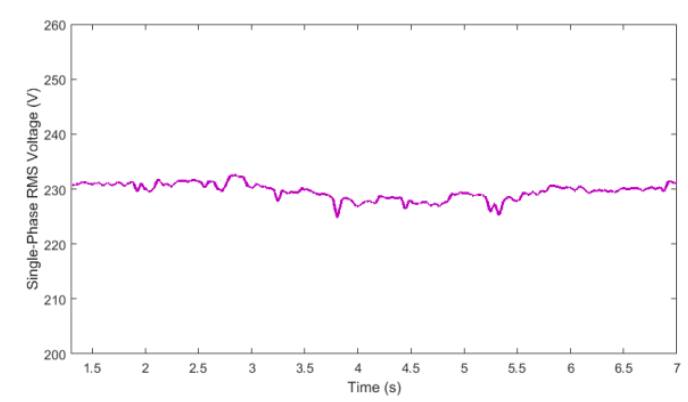

(b) Single-Phase Voltage

Fig. 29 Performance of the MG under grid-connected mode with commercial load

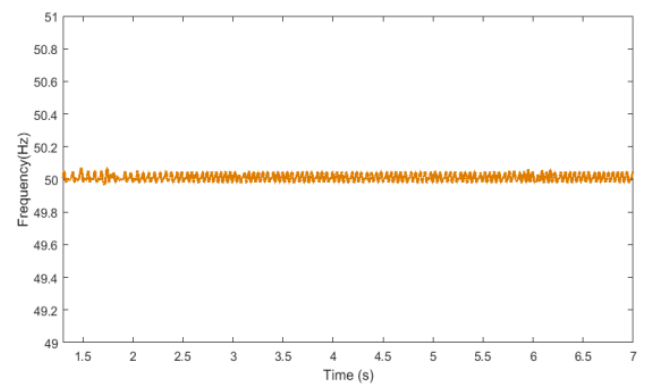

(a) Frequency

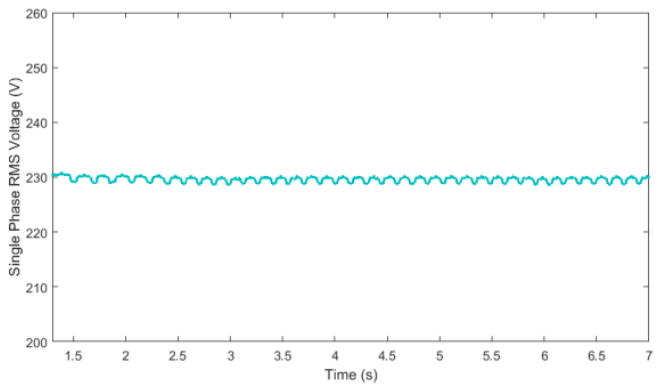

(b) Single-Phase Voltage

Fig. 30 Performance of the MG under islanding mode with constant load

\subsection{Hybrid AC/DC MG Tertiary Control Simulation}

The Hybrid AC/DC MG requires an EMS which pursues objectives such as peak shaving, energy storage scheduling, cost minimization, load balancing and etc. In order to make sure of the functionality of EMS before implementation on the experimental H-MG, a comprehensive modeling and simulation of the EMS are required. The modeling and simulation of EMS are based on the real data extracted from the H-MG via communication and monitoring system. A Rule-based scheduling algorithm developed in [41] has been explained in previous sections. This algorithm is employed as the basis for the tertiary control simulation in this section. The main objective of this algorithm is to shave the peak through charging and discharging of energy storage in the off-peak and peak hours respectively while minimizing the costs. The EMS runs for one day and provides the results of energy storage scheduling for one day. Table II and III show real data from experimental H-MG utilized for the EMS simulation. The data of 3th of August 2016 is chosen for simulation as it is the peak day of month August.

Table II. Energy Storage parameters for EMS Simulation [41]

\begin{tabular}{ll} 
BESS Parameters & Characteristics \\
\hline BESS Technology & Li-lon \\
\hline Rated Capacity & $60 \mathrm{kWh}$ \\
\hline Cycles (80\% DOD) & 7500 \\
\hline SOC limits & $20 \%-90 \%$
\end{tabular}

Table III. Time of Use Tariffs for energy (top) and demand (bottom) charges [41]

\begin{tabular}{lll} 
TOU Tariffs & Price & Time \\
\hline Peak & $9.7 \mathrm{c} / \mathrm{kWh}$ & $7 \mathrm{am}-8 \mathrm{pm}$ \\
\hline Off-peak & $6.6 \mathrm{c} / \mathrm{kWh}$ & $8 \mathrm{pm}-7 \mathrm{am}$ \\
\hline TOU Tariffs & Price & Time \\
\hline Peak & $24.14 \$ / \mathrm{kW}$ & All day long
\end{tabular}

As it is seen in the Fig. 31, for the specific day of the month which peak occurs, the EMS discharges the energy storage during the peak hours in order to reduce the peak and tries to minimize the cost of operation at the same time. By reducing the peak, MG is charged for lower peak demand. 


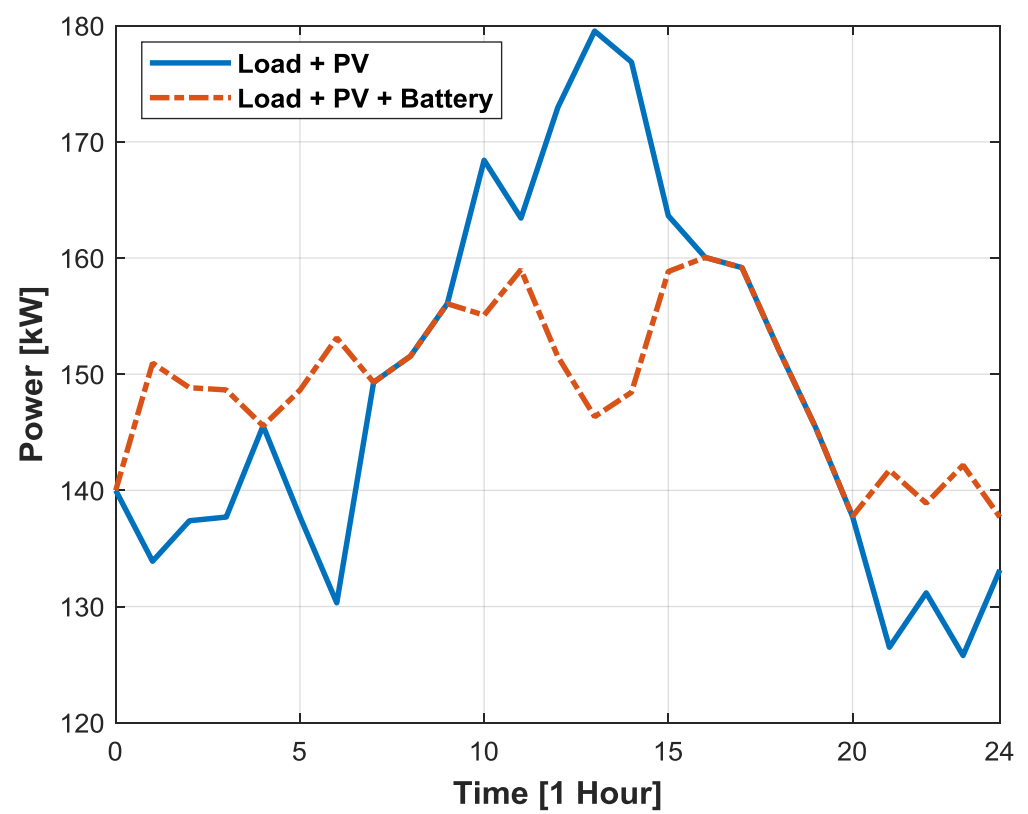

Fig. 31 Peak shaving simulation results employing experimental H-MG load and battery data

\section{Conclusion and Future Work}

The development of an H-MG is an ongoing process; changing with advances in semiconductor technology, energy storage technology, and distributed generation technologies. The design and installation of the AC/DC H-MG are presented in this paper, including communication and control system with advanced technology and architecture, performance testing along with hardware and software evaluation. Data has been collected and analyzed from a system level through to a component level. Testing on various DC/DC converter configurations and Statcom power electronic equipment. Simulation results of the various modes of the Microgrid, such as grid-connected mode and islanding mode have been investigated, proving the concept for further development. The real world experimental MG offers numerous advantages in areas of testing and development of converter technologies. An optimal design of the MG with load profile forecasting, phase balancing, and harmonics are yet to be investigated. Further investigation into the constructive and destructive impacts of EV on the MG, wind turbines on the roof and the Statcoms full fourquadrant functionality required.

\section{Acknowledgements}

The authors would like to thank the support by Queensland Government Smart-State Funding, Advance Queensland Research Fellowships Funding, Queensland Smart Future Project - Peak Demand Energy Management Project, Ergon Energy, Power IQ, EcoJoule Energy, Energex, Elevare Energy and Griffith University for their contribution.

\section{References}

[1] C. Munro, "2015-2016 Annual Report," C. E. Regulator, Ed., ed. Canberra, Australian Capital Terrortory, Australia: Clean Energy Regulator, 2016, pp. 1-203.

[2] C. Munro, "2015 Administrative Report and Annual Statement," C. E. Regulator, Ed., ed. Canberra, Australian Capital Territory Clean Energy Regulator, 2016, pp. 1 - 93.

[3] B. P. Roberts and C. Sandberg, "The Role of Energy Storage in Development of Smart Grids," Proceedings of the IEEE, vol. 99, pp. 1139-1144, 2011. 
[4] M. J. E. Alam, K. M. Muttaqi, and D. Sutanto, "Mitigation of Rooftop Solar PV Impacts and Evening Peak Support by Managing Available Capacity of Distributed Energy Storage Systems," IEEE Transactions on Power Systems, vol. 28, pp. 3874-3884, 2013.

[5] A. A. Solomon, D. M. Kammen, and D. Callaway, "The role of large-scale energy storage design and dispatch in the power grid: A study of very high grid penetration of variable renewable resources," Applied Energy, vol. 134, pp. 75-89, 12/1/ 2014.

[6] M. Welsch, P. Deane, M. Howells, B. Ó Gallachóir, F. Rogan, M. Bazilian, et al., "Incorporating flexibility requirements into long-term energy system models - A case study on high levels of renewable electricity penetration in Ireland," Applied Energy, vol. 135, pp. 600-615, 12/15/ 2014.

[7] I. Komušanac, B. Ćosić, and N. Duić, "Impact of high penetration of wind and solar PV generation on the country power system load: The case study of Croatia," Applied Energy, vol. 184, pp. 1470-1482, 12/15/ 2016.

[8] S. Alyami, Y. Wang, and C. Wang, "Overvoltage risk analysis in distribution networks with high penetration of PVs," in 2016 International Conference on Probabilistic Methods Applied to Power Systems (PMAPS), 2016, pp. 1-6.

[9] IEEE, "IEEE Standards Coordinating Commitee 21," in 1547.4 IEEE Guide for Design, Operation and Integration of Distributed Resource Island Systems with Electric Power Systems, ed. New York: IEEE, 2011, p. 54.

[10] J. Ekanayake, N. Jenkins, K. Liyanage, J. Wu, and A. Yokoyama, Smart Grid: Technology and Applications: WILEY, 2012.

[11] C. Gouveia, D. Rua, F. Ribeiro, L. Miranda, J. M. Rodrigues, C. L. Moreira, et al., "Experimental validation of smart distribution grids: Development of a microgrid and electric mobility laboratory," International Journal of Electrical Power \& Energy Systems, vol. 78, pp. 765-775, 2016.

[12] C. Wang, X. Yang, Z. Wu, Y. Che, L. Guo, S. Zhang, et al., "A Highly Integrated and Reconfigurable Microgrid Testbed with Hybrid Distributed Energy Sources," IEEE Transactions on Smart Grid, vol. 7, pp. 451-459, 2016.

[13] B. Zhao, X. Zhang, and J. Chen, "Integrated Microgrid Laboratory System," IEEE Transactions on Power Systems, vol. 27, pp. 2175-2185, 2012.

[14] T. V. Vu, D. Perkins, F. Diaz, D. Gonsoulin, C. S. Edrington, and T. El-Mezyani, "Robust adaptive droop control for DC microgrids," Electric Power Systems Research, vol. 146, pp. 95106, 2017.

[15] U. Manandhar, A. Ukil, and T. K. K. Jonathan, "Efficiency comparison of DC and AC microgrid," in 2015 IEEE Innovative Smart Grid Technologies - Asia (ISGT ASIA), 2015, pp. 1-6.

[16] B. E. Noriega, R. T. Pinto, and P. Bauer, "Sustainable DC-microgrid control system for electricvehicle charging stations," in 2013 15th European Conference on Power Electronics and Applications (EPE), 2013, pp. 1-10.

[17] R. H. Ashique, Z. Salam, M. J. Bin Abdul Aziz, and A. R. Bhatti, "Integrated photovoltaic-grid dc fast charging system for electric vehicle: A review of the architecture and control," Renewable and Sustainable Energy Reviews, vol. 69, pp. 1243-1257, 2017.

[18] P. García-Triviño, J. P. Torreglosa, L. M. Fernández-Ramírez, and F. Jurado, "Control and operation of power sources in a medium-voltage direct-current microgrid for an electric vehicle fast charging station with a photovoltaic and a battery energy storage system," Energy, vol. 115, Part 1, pp. 38-48, 11/15/ 2016.

[19] N. Sasidharan, N. Madhu M, J. G. Singh, and W. Ongsakul, "Real Time Active Power Ancillary Service Using DC Community Grid with Electric Vehicles and Demand Response," Procedia Technology, vol. 21, pp. 41-48, 2015/01/01 2015.

[20] N. Hatziargyriou, Microgrids: Architectures and Control, 1 ed. Chichester, West Sussex, United Kingdom: John Wiley \& Sons Inc, 2014. 
[21] M. S. Rahman, M. J. Hossain, and J. Lu, "Utilization of parked EV-ESS for power management in a grid-tied hybrid AC/DC microgrid," in Power Engineering Conference (AUPEC), 2015 Australasian Universities, 2015, pp. 1-6.

[22] L. Tzung-Lin, H. Shang-Hung, and C. Yu-Hung, "D-STATCOM With Positive-Sequence Admittance and Negative-Sequence Conductance to Mitigate Voltage Fluctuations in HighLevel Penetration of Distributed-Generation Systems," Industrial Electronics, IEEE Transactions on, vol. 60, pp. 1417-1428, 2013.

[23] F. H. M. Rafi, M. J. Hossain, D. Leskarac, and J. Lu, "Reactive power management of a AC/DC microgrid system using a smart PV inverter," in 2015 IEEE Power \& Energy Society General Meeting, 2015, pp. 1-5.

[24] Z. Yang, C. Shen, L. Zhang, M. L. Crow, and S. Atcitty, "Integration of a Statcom and battery energy storage," Power Systems, IEEE Transactions on, vol. 16, pp. 254-260, 2001.

[25] X. Liu, P. Wang, and P. C. Loh, "A Hybrid AC/DC Microgrid and Its Coordination Control," IEEE Transactions on Smart Grid, vol. 2, pp. 278-286, 2011.

[26] L. Meng, A. Luna, E. R. Díaz, B. Sun, T. Dragicevic, M. Savaghebi, et al., "Flexible System Integration and Advanced Hierarchical Control Architectures in the Microgrid Research Laboratory of Aalborg University," IEEE Transactions on Industry Applications, vol. 52, pp. 1736-1749, 2016.

[27] D. Aryani and H. Song, "Coordination Control Strategy for AC/DC Hybrid Microgrids in StandAlone Mode," Energies, vol. 9, p. 469, Jun 2016.

[28] X. Tang, X. Hu, N. Li, W. Deng, and G. Zhang, "A Novel Frequency and Voltage Control Method for Islanded Microgrid Based on Multienergy Storages," IEEE Transactions on Smart Grid, vol. 7, pp. 410-419, 2016.

[29] D. Leskarac, C. Bennett, M. Moghimi, S. Stegen, and L. Junwei, "Testing facility for research and development of Smart-MicroGrid technologies," in Power and Energy Engineering Conference (APPEEC), 2015 IEEE PES Asia-Pacific, 2015, pp. 1-5.

[30] M. Moghimi, C. Bennett, D. Leskarac, S. Stegen, and L. Junwei, "Communication architecture and data acquisition for experimental MicroGrid installations," in Power and Energy Engineering Conference (APPEEC), 2015 IEEE PES Asia-Pacific, 2015, pp. 1-5.

[31] M. A. Zehir, A. Batman, M. A. Sonmez, A. Font, D. Tsiamitros, D. Stimoniaris, et al., "Impacts of microgrids with renewables on secondary distribution networks," Applied Energy, Available online 5 January 2017.

[32] R. Atia and N. Yamada, "Sizing and Analysis of Renewable Energy and Battery Systems in Residential Microgrids," IEEE Transactions on Smart Grid, vol. 7, pp. 1204-1213, 2016.

[33] M. Moghimi, D. Leskarac, N. Nadian, S. Stegen, and J. Lu, "Impact of PEV behavior on peak demand reduction in a commercial microgrid," in 2016 Australasian Universities Power Engineering Conference (AUPEC), 2016, pp. 1-5.

[34] M. S. Rahman, M. J. Hossain, and J. Lu, "Coordinated control of three-phase AC and DC type EV-ESSs for efficient hybrid microgrid operations," Energy Conversion and Management, vol. 122, pp. 488-503, 8/15/ 2016.

[35] C. Bennett, M. Moghimi, M. J. Hossain, L. Junwei, and R. A. Stewart, "Applicability of load forecasting techniques for customer energy storage control systems," in Power and Energy Engineering Conference (APPEEC), 2015 IEEE PES Asia-Pacific, 2015, pp. 1-5.

[36] D. Leskarac, C. Panchal, S. Stegen, and J. Lu, "PEV Charging Technologies and V2G on Distributed System and Utility Interfaces," in Vehicle-to-Grid: Linking Electric Vehicles to the Smart Grid, Junwei Lu and Janhangir Hossain, Eds., ed. London, United Kingdom: The Institution of Electrical Engineers, 2015, pp. 157-221.

[37] F. Katiraei, "Dynamic analysis and control of distributed energy resources in a micro-grid," Dissertation/Thesis, ProQuest, UMI Dissertations Publishing, 2005. 
[38] S. Stegen and J. Lu, "Investigation of a Novel Integrated Magnetic System Using Finite Element Method in Comparison to Conventional Integrated Magnetic Devices," IEEE Transactions on Magnetics, vol. 48, pp. 695-698, 2012.

[39] K. D. Brabandere, B. Bolsens, J. V. d. Keybus, A. Woyte, J. Driesen, and R. Belmans, "A Voltage and Frequency Droop Control Method for Parallel Inverters," IEEE Transactions on Power Electronics, vol. 22, pp. 1107-1115, 2007.

[40] J. Liu, M. S. Rahman, J. Lu, and M. J. Hossain, "Performance investigation of hybrid AC/DC microgrids during mode transitions," in 2016 Australasian Universities Power Engineering Conference (AUPEC), 2016, pp. 1-6.

[41] M. Moghimi, D. Leskarac, C. Bennett, J. Lu, and S. Stegen, "Rule-based Energy Management System in an Experimental Microgrid with the Presence of Time of Use Tariffs," MATEC Web Conf., vol. 70, p. 10011, 2016.

[42] C. J. Bennett, R. A. Stewart, and J. W. Lu, "Forecasting low voltage distribution network demand profiles using a pattern recognition based expert system," Energy, vol. 67, pp. 200212, 4/1/ 2014.

[43] M. Gharbaoui, L. Valcarenghi, R. Bruno, B. Martini, M. Conti, and P. Castoldi, "An advanced smart management system for electric vehicle recharge," in Electric Vehicle Conference (IEVC), 2012 IEEE International, 2012, pp. 1-8. 